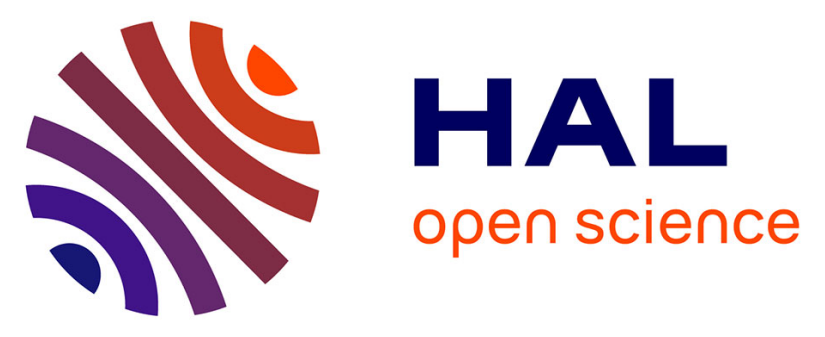

\title{
The antidiabetic drug glibenclamide exerts direct retinal neuroprotection
}

\author{
Marianne Berdugo, Kimberley Delaunay, Marie-Christine Naud, Justine \\ Guegan, Alexandre Moulin, Michèle Savoldelli, Émilie Picard, Lolita Radet, \\ Laurent Jonet, Zoubir Djerada, et al.
}

\section{To cite this version:}

Marianne Berdugo, Kimberley Delaunay, Marie-Christine Naud, Justine Guegan, Alexandre Moulin, et al.. The antidiabetic drug glibenclamide exerts direct retinal neuroprotection: Glibenclamide exerts retinal neuroprotection. American Journal of Translational Research, 2020, pp.S1931-5244(20)302449. $10.1016 / j . t r s l .2020 .10 .003$. inserm-02980520

\section{HAL Id: inserm-02980520 https://www.hal.inserm.fr/inserm-02980520}

Submitted on 27 Oct 2020

HAL is a multi-disciplinary open access archive for the deposit and dissemination of scientific research documents, whether they are published or not. The documents may come from teaching and research institutions in France or abroad, or from public or private research centers.
L'archive ouverte pluridisciplinaire HAL, est destinée au dépôt et à la diffusion de documents scientifiques de niveau recherche, publiés ou non, émanant des établissements d'enseignement et de recherche français ou étrangers, des laboratoires publics ou privés. 


\title{
TITLE
}

\section{The antidiabetic drug glibenclamide exerts direct retinal neuroprotection}

\author{
ABBREVIATED TITLE \\ Glibenclamide exerts retinal neuroprotection
}

\section{AUTHORS}

MARIANNE BERDUGO ${ }^{1,2,3}$, KIMBERLEY DELAUNAY ${ }^{1,2,3},{ }^{,}$MARIE-CHRISTINE NAUD $^{1,2,3}$, JUSTINE GUEGAN ${ }^{4}$ ALEXANDRE MOULIN $^{5}$, MICHELE SAVOLDELLI ${ }^{1,2}$, EMILIE PICARD ${ }^{1,2,3}$, LOLITA RADET ${ }^{1,2,3}$, LAURENT JONET ${ }^{1,2,3}$, ZOUBIR DJERADA ${ }^{6}$, CLAIRE GOZALO $^{6}$, ALEJANDRA DARUICH ${ }^{1,2,3,7}$, JACQUES BELTRAND ${ }^{1,8,9,10}$, JEANCLAUDE JEANNY ${ }^{1,2,3}$, ELSA KERMORVANT-DUCHEMIN ${ }^{1,2,11}$, PATRICIA CRISANTI ${ }^{1,2,3}$, MICHEL POLAK ${ }^{1,8,9,10}$, FRANCINE BEHAR-COHEN $N^{1,2,3,12 *}$

${ }^{1}$ Université de Paris, Faculté de Médecine, Paris, France.

${ }^{2}$ Inserm UMRS 1138, Team 17: Physiopathology of ocular diseases-Therapeutic innovations, Centre de Recherche des Cordeliers, Paris, France.

${ }^{3}$ Université Pierre et Marie Curie, Sorbonne Université, UMR_S 1138, Centre de Recherche des Cordeliers, Paris, France.

${ }^{4}$ iCONICS Corefacility, ICM Institut du Cerveau et de la Moelle épinière, Hôpital de la Pitié-Salpêtrière, Paris, France

${ }^{5}$ Department of Ophthalmology of University of Lausanne, Jules Gonin Hospital, Fondation Asile des Aveugles, 1000 Lausanne, Switzerland

${ }^{6}$ Laboratoire de Pharmacologie-Toxicologie, Hôpital Maison Blanche, centre hospitalier et universitaire de Reims, Reims, France

${ }^{7}$ AP-HP, Service d'Ophtalmologie, Hôpital Universitaire Necker Enfants Malades, Paris, France

${ }^{8}$ AP-HP, Service d'Endocrinologie, Gynécologie et Diabétologie Pédiatriques, Hôpital Universitaire Necker Enfants Malades, Paris, France

${ }^{9}$ Inserm U1016, Institut Cochin, Paris, France

${ }^{10}$ Inserm UMR 1163, Institut Imagine, Paris Descartes-Université Sorbonne Paris Cité, Paris, France

${ }^{11}$ AP-HP, Service de Néonatalogie, Hôpital Universitaire Necker Enfants Malades, Paris, France

${ }^{12}$ AP-HP, OphtalmoPôle, Hôpital Cochin, Paris, France

marianne.berdugo@inserm.fr; kimberley.delaunay@live.fr;marie-

christine.naud@crc.jussieu.fr;justine.guegan@icm-

institute.org;alexandre.moulin@fa2.ch;savoldellimichele17@gmail.com;emilie.picard@crc.jussieu.fr;lolitaradet@g mail.com; laurent.jonet@crc.jussieu.fr; zdjerada@chu-reims.fr; cgozalo@chu-reims.fr; adaruich.matet@gmail.com; jacques.beltrand@aphp.fr; jean-claude.jeanny@orange.fr; elsa.kermorvant@aphp.fr; patricia.lassiaz@crc.jussieu.fr; michel.polak@aphp.fr

*Correspondence and requests for materials should be addressed to:

F.B.-C. Email: francine.behar@gmail.com; Phone: +33 144278164 or 69; Centre de Recherche des Cordeliers UMRS 1138, Equipe 17, 15 rue de l'Ecole de Médecine 75006 Paris, France 


\begin{abstract}
Sulfonylureas, widely used as hypoglycaemic agents in adults with type 2 diabetes, have neuroprotective effects in preclinical models of central nervous system injury, and in children with neuropsychomotor impairments linked to neonatal diabetes secondary to ATP-sensitive potassium channel mutations. In the human and rodent retina, we show that the glibenclamide activated channel SUR1 is expressed in the retina and enriched in the macula; we also show that it co-localizes with the potassium channel Kir6.2, and with the cation channel transporter TRPM4. Glibenclamide (glyburide), administered at doses that did not decrease the glycaemia, or injected directly into the eye, protected the structure and the function of the retina in various models of retinal injury that recapitulate the pathogenic neurodegenerative events in the diabetic retina. The down-regulation of SUR1 using a siRNA suppressed the neuroprotective effects of glibenclamide on excitotoxic stress-induced cell death. The glibenclamide effects include the transcriptional regulation of anti-oxidant and neuroprotective genes. Ocular glibenclamide could be repurposed for diabetic retinopathy.
\end{abstract}

Keywords: Glibenclamide; Sulfonylurea; Retinal neuroprotection; Diabetic retinopathy; Retinal neurodegeneration animal models 


\section{INTRODUCTION}

The prevalence of diabetes worldwide is expected to reach $7.7 \%$ by $2030{ }^{1}$ and could reach about $12 \%$ in large cities in the USA. ${ }^{2}$ Diabetic retinopathy is the major cause of vision loss in the working-age population of western countries, and a growing health concern in emerging countries. After 10 years, $50 \%$ of types 1 and $30 \%$ of type 2 diabetic patients have retinal microvascular complications. ${ }^{3}$ In diabetes, vision loss results from two major complications, macular edema and retinal cell death. Indeed, an early and progressive deterioration of electrical retinal responses, with loss of electrical signal amplitudes and extended response times, reflects retinal neuron alterations. ${ }^{4,5}$ The underlying mechanisms include neuroinflammation, metabolic disturbance, and deregulation of glutamate metabolism. ${ }^{6}$ While repeated intraocular injections of anti-VEGF (targeting the vasogenic component) or corticosteroids (which also target inflammation) can reduce macular edema, there is currently no clinically available treatment to stop or even slow down retinal neurodegeneration.

Sulfonylureas are an old class of antidiabetic drugs that, through binding to the sulfonylurea receptor (SUR), which is part of the regulatory subunit of $\mathrm{K}_{\mathrm{ATP}}$ (SUR1-Kir6.2)and TRPM4 (NC $\mathrm{Ca}_{\mathrm{ATP}}$ )-channels, provokes insulin secretion by the pancreas. Sulfonylureas, widely used for many years worldwide to manage type- 2 diabetes in adults, ${ }^{7}$ now appear also as cerebral neuroprotective agents. ${ }^{8-10}$ SUR1 is expressed in neurons, astrocytes, oligodendrocytes, endothelial cells, and by reactive microglia and, in cerebral ischemia model, glibenclamide reduced brain edema and was neuroprotectant. ${ }^{11}$ Recently, children presenting a potassium channel mutation-linked diabetes showed improved neuropsychological development when treated orally with glibenclamide (glyburide), an effect that was not observed when their diabetes was treated with other hypoglycaemic drugs. ${ }^{12}$ But the direct effect of glibenclamide on the retina is unknown. The aim of this study was to evaluate whether glibenclamide exerts direct effects on the retina, independently from 
its hypoglycaemic action, using different models of retinal pathology to recapitulate as much as possible human diabetic retinopathy.

We demonstrate herein that SUR1 is expressed in the retina in three different animal models, as well as in human and non-human primate retinas, where it is enriched in the macula. Using intraocular injections, we showed that glibenclamide protects against excitotoxic stress in vivo, at levels that can be reached in the eye using non-hypoglycaemic oral dose of glibenclamide. Such doses did improve the function and the structure of the diabetic retina in two rodent models, prompting to repurpose glibenclamide for retinal neuroprotection in diabetic retinopathy.

\section{RESEARCH DESIGN AND METHODS}

Primate human and non-human ocular tissues. The use of human tissues adhered to the tenets of the Declaration of Helsinki and was approved by the local ethics committee of the Swiss Department of Health on research involving human subjects (CER-VD N³40/15 and CER-VD N¹9/15), and patients signed informed consent.

One retina was obtained from an enucleated eye from a non-diabetic patient (female, 56 years old) with a tumor and intact posterior retina (untreated anterior uveal melanoma). The posterior retina was used for immunohistochemistry on cryosections as previously described. ${ }^{13}$ Due to the enucleation procedure, fresh tissues were available for analysis. Two euthanized monkey eyeballs were obtained from one African green monkey (Chlorocebus sabaeus) and one cynomolgus macaque (Macaca fascicularis) and stored in 4\% paraformaldehyde at $4^{\circ} \mathrm{C}$. Their flat-mounted neuroretinas were used for immunohistochemistry.

\section{Immunohistochemical analysis of monkey and human retinal tissues.}


Immunohistochemical methods are detailed in Supplemental Materials.

Rats. In this study, we used 6-8-week-old Wistar and Lewis rats (Janvier Laboratory, Le Genest-St-Isle, France), and 18-month-old Goto-Kakizaki (GK) rats (a Wistar strain of nonobese type 2 diabetic rats) (Taconic Europe, Denmark). In GK and Wistar rats, non-fasting blood glucose was measured at the tail vein with Accutrend GC and Accu-check compact equipment (Roche) and HbAlc was measured with A1C NOW+ multitest system (Bayer, Germany). We defined a plasma glucose level $>250 \mathrm{mg} / \mathrm{dL}(14 \mathrm{mmol} / \mathrm{L})$ as diabetic. In contrast to the control Wistar rats, male GK rats develop hyperglycaemia at approximately 14 weeks of age. Control age-matched Wistar rats (WS) were normoglycaemic. The strain is raised in our animal facility and the males only enter the experiments: group formation depended on the number of available males of the needed age.

All experimental procedures were performed in accordance with the Association for Research in Vision and Ophthalmology (ARVO) statement for the use of animals in Ophthalmic and Vision Research as well as with the UE directive 2010/63/EU. Experimental procedures were approved by the local ethics committee, European Council Charles Darwin of the University Paris Descartes (authorization 05-Ce5/2012/143-03952.03, A75-580). All procedures were performed under general (ketamine+xylasine) and local (oxybuprocaine, Novesine ${ }^{\circledR}$ Novartis Ophthalmics, Basel, Switzerland) anaesthesia. Animals were sacrificed with intraperitoneal sodium pentobarbital $(150 \mathrm{mg} / \mathrm{kg})$ before eyes were enucleated.

Animal models. Three complementary rat models of retinal neurodegeneration were used:

\section{1) N-methyl-D-aspartate (NMDA)-induced retinal excitotoxicity in the adult rat}

Retinal glial Müller cells normally collect glutamate from the extracellular space and recycle it to glutamine for photoreceptor use. Intravitreal injection of NMDA (45 nmol in 3 $\mu \mathrm{L}$ of balanced salt solution; BSS, Bausch \& Lomb, Ireland) in rat eyes reproduces a high 
extracellular glutamate concentration and induces neuroretinal cell death, through an apoptotic mechanism beginning in the inner retinal layers (ganglion cells and bipolar cells) around 16 hours after injection. ${ }^{14}$ This excitotoxic phenomenon corresponds to a massive influx of $\mathrm{Ca}^{2+}$ ions in neurons. Animals were randomly assigned to NMDA or vehicle treatment and they were sacrificed at 24 hours after the injection.

\section{2) Goto-Kakizaki (GK) diabetic rat}

The GK rat model is a non-obese model of non-insulin dependent (type 2) diabetes mellitus, in which animals develop late complications such as retinopathy, microangiopathy, neuropathy, and nephropathy. ${ }^{15}$ In this model, we have previously shown that diabetic retinopathy involves breakdown of blood retinal barriers (BRB) upon hyperglycaemia, related to PKCzeta overactivation as well as photoreceptor neurodegeneration. ${ }^{16,17}$ The model exhibits metabolic, hormonal, and vascular disorders similar to human diabetic disease. Only male rats develop type-2 diabetes at approximately 14-16 weeks of age. Characteristics include fasting hyperglycaemia, impaired secretion of insulin in response to glucose both in vivo and in isolated pancreatic cells, hepatic and peripheral insulin resistance, and polyuria. Our experiments were performed in 20-months old male GK rats, at advanced stage of retinopathy.

\section{3) Neonatal hyperglycaemia-induced retinal (NHIR) neurodegeneration model in the rat}

We previously developed a new model of transitory neonatal hyperglycaemia, based on injection of low dose streptozotocin $(50 \mathrm{mg} / \mathrm{kg})$ in postnatal day 1 (P1 or PN1) rat pups, which leads to a rapid and transient increase of glycaemia from P2/3 to P6 without affecting rat pups weight gain nor necessitating insulin treatment. This model mimics the effect of hyperglycaemia on the inner retina since it induces a rapid apoptotic death of ganglion cells. ${ }^{18}$ Because experiments began at post-natal day 1, pups births occurred in our animal facility, 
which determined the number of pups available for each experiment. Experiments were repeated.

Glibenclamide treatments. All treatment protocols are displayed in Supplemental Fig 1. Glibenclamide was administered either orally or intravitreally (once, twice or 3 times at $48 \mathrm{~h}$ intervals). Rats were randomly assigned to glibenclamide or vehicle treatment; they were submitted to general and local anaesthesia. For intravitreal injections, 4.5-mg glibenclamide (Sigma, UK) were diluted in $300-\mu \mathrm{L}$ dimethylsulfoxide (DMSO, Sigma, UK), and extemporaneously re-diluted in BSS to obtain $100,1,0.01$, or $0.001 \mathrm{ng}$ in $3 \mu \mathrm{L}$ ( $\mathrm{n}=8$ to 16/group). We used $31 \mathrm{G}$ needles for intravitreal injections under an operating microscope. Glibenclamide solution could be intravitreally co-injected with NMDA or preventively injected 5 days before. For oral administration to adult rats, we used $10-\mathrm{mg} / \mathrm{kg}$ oral glibenclamide suspension (Amglidia ${ }^{\circledR} 0.6 \mathrm{mg} / \mathrm{mL}$, AMMTeK distributed by Amring/Nordic, France). For newborn rats, the same oral formulation was administered at $210 \mu \mathrm{g} / \mathrm{kg}$ BID, from $\mathrm{P} 2$ to $\mathrm{P} 7$ via a pipette $(\mathrm{n}=5$ in normoglycaemic/vehicle group; $\mathrm{n}=8$ in hyperglycaemic/vehicle group, $\mathrm{n}=9$ for the hyperglycaemic/glibenclamide group). Control vehicle solutions were made of diluted DMSO, or BSS, or a glibenclamide-free oral suspension.

In vivo electrophysiology recordings and analyses. Bilateral full-field ERG responses were recorded 5 days before (as baseline recording) and after the injections (24 hours after NMDA injection, immediately before sacrifice). Variation in electrical responses before and after injections was studied. Rats were dark-adapted for $18 \mathrm{~h}$ and anesthetized with an intramuscular injection of a mixture of ketamine and xylazine. The cornea was desensitized with a drop of oxybuprocaine (Novesine ${ }^{\circledR}$ Novartis Ophthalmics, Basel, Switzerland) and the pupils were dilated with tropicamide (Novartis Ophthalmics).

Recordings were performed with the Ganzfeld VisioSystem device (Siem Biomedicale, 
Nîmes, France) sending light flashes. For scotopic electroretinograms, representing essentially rod-driven responses, flash intensities ranged from 0.0003 to $10 \mathrm{~cd} . \mathrm{s} / \mathrm{m}^{2}$. For photopic electroretinograms, representing essentially cone-driven responses, rats were light adapted for 5 minutes. In both conditions, 5 responses were averaged. Mixed responses refer to whole retinal responses (coming from both cone and rod-driven pathways). More technical details are provided in Supplemental Data. Negative a-waves amplitudes were measured from baseline to trough bottom. Positive b-waves amplitudes were measured in a blind way, from the b-wave trough bottom to its peak. Implicit times of the a- and b- waves were measured from time of stimulus to peaks. Pre-treatment values were subtracted from post-treatment ones. Results were expressed in microvolts $(\mu \mathrm{V})$ for amplitude changes and milliseconds (ms) for implicit time changes $($ mean \pm SEM). Values are automatically produced by the software and cannot be influenced by experimenters. ERG experiments on NMDA model were repeated 3 times ( $n=6$ to 12 eyes per group).

Assessment of cell survival and death. We assessed cell survival/cell death using two methods.

1) Ganglion cell microscope counting in neonate rats. We counted total ganglion cell nuclei on retinal historesin sections (passing through the optic nerve, and at precise distance from optic nerve) labelled with toluidine blue, in a double-blind fashion. The mean and SEM were calculated in each group: 1) normoglycaemic pups; 2) placebo-treated hyperglycaemic pups; and 3) glibenclamide-treated hyperglycaemic pups $(n=4-15)$. Ganglion cell counting in neonate rats experiment was repeated twice as previously described. ${ }^{18}$

2) Cell death assessment with TUNEL assay. A terminal deoxynucleotidyl transferase mediated biotinylated UTP nick end labelling (TUNEL) assay was performed following the manufacturer's instructions (Roche Diagnostics, Mannheim, Germany). Retinal sections were examined with a fluorescence microscope (BX51, Olympus, Rungis, France) and 
photographed with identical exposure parameters for all samples to be compared. Details are provided in Supplemental Online Data. For blind quantification of TUNEL + cells, 6-8 pictures were taken all over each retina having received either vehicle, or NMDA, or NMDA + glibenclamide. Results were expressed as a number of apoptotic cells/unit area (ImageJ software (NIH)). Those counts were averaged/retina and /group. This experiment showing reduction of retinal apoptosis by glibenclamide was repeated twice $(n=8-16)$.

\section{Rat retinal tissue preparation, immunohistochemistry, and histopathological} analyses.

1) Flat-mounted retinas and whole eyeball sections. Freshly enucleated eyes (superior pole tagged with suture, $n=4 /$ time point) were fixed and cryosectioned according to the protocol detailed in Supplemental Online Data.

2) Immunohistochemistry. $10-\mu \mathrm{m}$ thick cryosections were incubated with different primary antibodies, as follows: rabbit anti-SUR1 (Santa Cruz, CA, USA), goat anti-TRPM4 (Santa Cruz, CA, USA), mouse anti-Kir6.2 (Santa Cruz, CA, USA), rabbit anti-CRALBP (homemade), mouse anti-glutamine synthetase (Millipore, Molsheim, France), rabbit anti-red/green opsin (Millipore, Molsheim, France), goat anti-blue opsin (Santa Cruz, CA, USA), mouse anti-CD31 (BD Biosciences, New Jersey, USA), anti-alpha SMA (AFFYMETRIX, San Diego, USA), anti-peanuts agglutinin (VECTOR, CA, USA). Control sections were incubated without primary antibodies. The corresponding Alexa-conjugated secondary antibodies (Invitrogen, CA, USA) were used and sections were counterstained with DAPI (1:5000; Roche Diagnostics, France). In Supplemental Table 1 all used antibodies and reagents are displayed.

3) Historesin. Oriented ocular globes were fixed and embedded in resin according to the protocol described in Supplemental Online Data.

For quantification of live ganglion cells, ganglion cell nuclei were counted in the GCL and 
expressed as number of ganglion nuclei per picture. The number of GCL nuclei/picture was counted in 2 central and 2 peripheral pictures per retina, and averaged. Mean number of GCL nuclei/picture was calculated for each retina, and the mean count for each group was compared. For quantification of live bipolar cells (not shown), the area of the bipolar nuclear layer (inner nuclear layer, INL) was measured on both central and peripheral retina sections (4 sections), expressed as INL area per picture, and averaged for each retina as previously described. ${ }^{18}$ Kruskal-Wallis and Dunn's multiple comparison post-test were used.

4) Semi-thin section analysis. Eyes from GK rats were included in epoxy resin, oriented; 1$\mu \mathrm{m}$ thick semi-thin sections were cut with an ultra-microtome Reichert Ultracut E (Leica, Wetzlar, Germany), observed and photographed with a transmission electron microscope (TEM, JEOL 100 CX II (JEOL)). Detailed are given in the Supplemental Online Data.

\section{RNA-sequencing data analysis}

Quality of raw data was evaluated with FastQC. Poor quality sequences were trimmed or removed with Fastp software to retain only good quality paired reads. Star v2.5.3a ${ }^{19}$ was used to align reads on reference genome Rn6 using standard options. Quantification of gene and isoform abundances was done with rsem 1.2.28. ${ }^{20}$ Finally, normalisation and differential analysis were conducted with edger ${ }^{21}$ bioconductor package. Multiple hypothesis adjusted pvalues were calculated with the Benjamini-Hochberg procedure to control FDR.

Functional enrichment analysis was done with cluster Profiler bioconductor package on the differentially deregulated genes with over-representation analysis and on all the genes with Gene Set Enrichment analysis. Hallmark molecular signatures database and WikiPathways were used.

SUR1 gene silencing expression by in vivo siRNA delivery. A dried SUR1 siRNA mix, comprising three to five target-specific sequences (19-25 nucleotides; sc-42634, Santa Cruz 
Biotechnology, CA, USA) was injected into the vitreous of rat eyes, alone or along with NMDA, or with NMDA and glibenclamide 0,001 ng/eye. Animals were killed $48 \mathrm{~h}$ later. Details are provided in Supplemental Data as well as methods for fluorescence quantification.

Glibenclamide dosing method in ocular fluids is described in Supplemental Materials.

Statistics. In electroretinography experiments, we performed ERG before and after injections/treatments; for each ERG parameter of each animal eye, we subtracted pre treatment values from post treatment values of the same eye, generating values, for each parameter, representing its evolution or "change" induced by treatments/injections. Those changes are presented in the Fig 4 and supplemental Fig 7 graphs. They were compared in all groups by a Kruskal-Wallis ANOVA test - to test for normality $(P=0.05)$ - followed by a oneto-one multiple comparison Dunn's test or a grouped Bonferroni post-test. Data are presented as the mean change \pm SEM and were evaluated with Prism software. In newborn rat protection of retinal cells experiments (Fig 5), the number of GCL nuclei/picture was counted in 2 central and 2 peripheral pictures per retina. Mean number of GCL nuclei/picture was calculated for each retina, averaged per group, and compared between the 3 groups using Kruskal-Wallis followed by multiple comparison Dunn's test. Values of $P<0.05$ were considered significant. In other experiments involving 2 groups only, glycaemia/animal, fluorescence $(\mathrm{CTCL}) /$ picture were calculated and averaged \pm SEM and non-parametric MannWhitney test was performed; $\mathrm{P}<0.05$ was considered significant. 


\section{RESULTS}

\section{SUR1, expressed in human and non-human primate retina, is enriched in the macula and co-localizes with TRPM4 and with Kir6.2}

In the normal human macula (Fig 1 and 2), SUR1 is expressed in all retinal layers, including the ganglion cell layer (GCL), the outer plexiform layer (OPL, i.e. synapses), the outer nuclear layer (ONL, i.e. photoreceptor nuclei layer), and at the outer limiting membrane (OLM) formed by junctions between photoreceptors and glial Müller cells, which is part of the outer retinal barrier; it is also expressed in retinal vessels (Fig 1 A inset). Co-localization with glutamine synthetase (GS), which is a marker of Retinal Müller Glial cells (RMG), shows SUR1 expression along the RMG (Fig 1A). In the fovea, the most important region responsible for visual acuity, SUR1 is expressed along the cone photoreceptors, in the Zshaped Müller glial cells and at the OLM (Fig 1A lower inset). In the peripheral human retina (Fig 1B), SUR1 is detected in GCL nuclei, in Müller glial cells (Fig 1B inset), in the OPL, in some photoreceptors and at the OLM.

Co-labelling of SUR1 with specific cone markers shows that SUR1 is expressed in blue cones and in red/ green cones (Fig 1C).

SUR1 co-localizes in pancreatic beta cells with the inward rectifier potassium channel 6.2 (Kir6.2), and in the brain with the transient receptor potential cation channel member-4 (TRPM4). ${ }^{22}$ In the human retina, we detected TRPM4 in human retinal astrocytes (Fig 2A, arrows), in the GCL (Fig 2A insets), at the OLM (Fig 2C) and in cone photoreceptors where it colocalized partially with SUR1 (Fig 2C). Kir6.2 showed same localization but with additional expression in the cells of the inner nuclear layer (INL, containing interneuron, bipolar and Müller cell nuclei) and around retinal vessels (Fig 2A insets). Co-labelling with aSMA and CD31 confirmed that SUR1 is expressed in endothelial cells but not in smooth 
muscle cells (Fig 2B), suggesting that perivascular SUR1 and Kir6.2 stainings could correspond to perivascular RMG. Furthermore, Kir6.2 was not expressed in retinal astrocytes.

In the human retina, SUR1 co-localizes partially with TRPM4 and/or Kir6.2 at the OLM (Fig 2C), in photoreceptors (particularly cones), in the ganglion cell layer and in endothelial cells of the inner retina vessels.

On non-human primate retina flat-mount (Fig 3), the macula is easily detected as it is enriched in RMG cells and in cones (Fig 3A). SUR1 is enriched in the macula (Fig 3B) and partly co-localized with the glial protein glutamine synthetase (GS) at the fovea border, as well as at the bottom of the foveal pit. Also in the fovea, TRPM4 and Kir6.2 co-localized with SUR1 in the Müller glial cells and in cones (not shown).

Co-localization of SUR1 with TRPM4 and with Kir6.2 is observed in the nerve fibre layer (made of ganglion cells axons conducting the signal through the optic nerve), in the GCL (Fig 3C), and at the OLM (Fig 3C), suggesting that TRPM4 and Kir6.2 may be partners of SUR1 in the retina.

\section{Intraocular glibenclamide improves the retinal function of adult rat models of diabetic retinopathy and excitotoxicity}

Glycaemia remained stable after intraocular administration of glibenclamide (0.001 ng/eye) in 20 months-old GK rats [Supplemental Figure 3], allowing evaluating the effect of glibenclamide on retinal cells independently from its hypoglycaemic effect.

Electroretinography (ERG) was used to evaluate the effect of glibenclamide on retinal function in an acute excitotoxicity rat model and in type 2 diabetic rats. Intravitreal injection of N-methyl-D-aspartate (NMDA) induces an acute excitotoxic stress and subsequent loss of function (Fig 4A-F). A significant dose-dependent preservation of the a- and b-waves, which represent respectively photoreceptor and inner retinal activities (that follows photoreceptor 
signals), was induced by intraocular glibenclamide (1, 0.01 or $0.001 \mathrm{ng} / \mathrm{eye})$, both at the time

of NMDA injection (A, C, E) and preventively 5 days before (100 ng/eye) (B, D, F). In 20months-old Goto-Kakizaki (GK) rats, a model of type 2 diabetes mellitus with many features of human retinopathy, ${ }^{16,17,23,24}$ local intravitreal administration of glibenclamide at a dose of $0.001 \mathrm{ng} /$ eye (3 times at 48 -hour intervals), which had no effect on glycaemia, induced a significant improvement in whole retinal activities (Fig 4G-L). B-wave implicit times were reduced and blue a-wave ones showed the same tendency, suggesting that both inner and outer retina function were improved (Fig 4G-L). Intraocular glibenclamide thus exerts direct effects on retinal function in two rat models that recapitulate the neuronal cell dysfunction occurring in diabetic retinopathy.

\section{Glibenclamide protects against retinal cell death in neonatal and adult rodent models}

\section{of excitotoxicity and hyperglycaemia}

Neuroprotection was evaluated in two models of hyperglycaemia and in the NMDAinduced excitotoxic model. Transient neonatal streptozotocin-induced hyperglycaemia (at PN1) causes death of ganglion and bipolar cells at day $14^{18}$ similar to the early neurodegenerative changes occurring in the inner retina of hyperglycaemic patients before any detectable microvascular change. ${ }^{25}$ As in new-born animals visual function cannot be assessed yet (eyelids are closed), only retinal structure was evaluated in this model. An oral glibenclamide paediatric suspension (Amglidia ${ }^{\circledR} 0.6 \mathrm{mg} / \mathrm{mL}$, AMMTeK, France distributed by Nordic) administered between PN2 and PN7, at a dose that did not significantly reduce blood glucose (210 $\mu \mathrm{g} / \mathrm{kg}$ PO BID) [Supplemental Fig 3], protected the ganglion cell layer (GCL) $(P=0.0101$, multiple comparison Dunn's test) (Fig 5A-B) and the bipolar cell layer (not shown, $P=0.05$ ). SUR1 was expressed in pup retinas from PN2, and it was increased at PN3 and PN4 when streptozotocin was injected, as shown by PCR [Supplemental Fig 4]. 
In 20-months old diabetic GK rats (Fig 5C), diabetic retinopathy manifests as vacuolization and swelling of the Müller glial cells, disorganization and disappearance of photoreceptor segments, and swelling of the outer retina (Fig 5C). Intraocular glibenclamide (3 injections of $0.001 \mathrm{ng} /$ eye every other day) reduced the swelling of the Müller cells, restored the outer retina morphology and improved the alignment of the photoreceptor segments, supporting an anti-edematous effect (Fig 5C). In the NMDA-induced excitotoxic model (Fig 5D), injection of 1 or $0.01 \mathrm{ng}$ glibenclamide/eye at the time of NMDA administration reduced the number of TUNEL positive apoptotic cells counted $24 \mathrm{hrs}$ after NMDA injection by $44.25 \%$ and $47.1 \%$ respectively (Kruskal-Wallis test $P=0.0146$ was followed by Dunn's test; $1 \mathrm{ng}$ glibenclamide vs. NMDA alone: 40.23 $\pm 4.04 / 22.43 \pm 4.25$, $P<0.05 ; 0.01 \mathrm{ng}$ glibenclamide vs. NMDA alone: $21.3 \pm 4.7 /$ eye, $P<0.05)$. A more drastic reduction of apoptosis was achieved with preventive glibenclamide treatment, administered 5 days before excitotoxic stress was induced. Indeed, reductions of $77.1 \%$ and $87.1 \%$ in retinal apoptotic cell death were observed with glibenclamide $100 \mu \mathrm{g}$ or $100 \mathrm{ng} / \mathrm{eye}$, respectively (Kruskal-Wallis $P<0.001 ; 10.07 \pm 2.87$ or $5.95 \pm 0.75$ vs. TUNEL positive cells/eye, Dunn's test $P=0.0001$ and $P<0.0001$ vs. NMDA alone, respectively) (Fig 5D).

Glibenclamide exerts neuroprotective and anti-edematous effects in various models of retinal pathology through its interaction with SUR1, expressed on both glial and neuronal retinal cells.

\section{SUR1, TRPM4 and Kir6.2 retinal distribution is altered in excitotoxic and \\ hyperglycaemic conditions}

Immunohistochemical staining on normal rat retinal sections and whole inner retina flatmounts (Fig 6) showed intense SUR1 signal throughout all retinal layers (Fig 6A). SUR1 was localized in retinal ganglion cells (Fig 6A inset), along glial Müller cells (Fig 6A, co-localized with GS) and in the outer nuclear layer. TRPM4 partly co-localized with SUR1 in retinal 
astrocytes (Fig 6A flat-mount and inset) whilst Kir6.2 co-localized partly with SUR1 in ganglion cells (Fig 6A flat-mount and inset) and in the inner nuclear cells. After excitotoxic stress (Fig 6B), SUR1 immunoreactivity increased in the retinal layers, including the ganglion cell layer (Fig 6B inset), at the outer plexiform layer, the ONL and in Müller glial cells (Fig 6B co-labelling with GS, inset) as compared to control (Fig 6A). SUR1 expression was increased in the nerve fibre layer where astrocytes expressing TRPM4 were detected (Fig 6B flat-mounts and inset). Kir6.2 mostly co-localized with SUR1 in ganglion cells (Fig 6B flatmount and inset). In 1 year-old GK rat (Fig 6C), SUR1 was mostly observed in the GCL (Fig 6C and flat-mount inset) and showed intense accumulation at the OLM (Fig 6C arrows, and co-staining with GS, inset), co-localizing with TRPM4 (not shown). TRPM4 expression seemed reduced in astrocytes (Fig 6C flat-mount and inset). In the neonatal hyperglycaemic model, SUR1 expression was also transiently up-regulated at PN3 and PN4 [Supplemental Fig 4].

In summary, in diabetic and excitotoxic conditions, SUR1 expression increases in the inner retina, the RMG cells and it concentrates in the end-feet of retinal Müller glial cells, at the OLM in diabetic conditions. In the rodent neuroretina, TRPM4 consistently co-localized with Kir6.2 in the inner retina and at the OLM [Supplemental Figure 6].

\section{The protective effect of glibenclamide is mediated by SUR1}

A single intraocular injection of a siRNA directed against SUR1 reduced SUR1 expression by $44.6 \%$ [Supplemental Figure 7]. Pre-treatment with the siRNA abolished the neuroprotective effect of $0.001 \mathrm{ng}$ glibenclamide against NMDA-induced apoptosis, demonstrating that glibenclamide exerts its effects through binding to its receptor SUR1 on retinal cells. 


\section{Transcriptomic signature of intraocular glibenclamide in the diabetic retina}

To explore the mechanisms mediating the beneficial effects of glibenclamide on the retinal function and pathology of the GK rat, we performed a full transcriptomic analysis at 5 hours after 2 intravitreal injections of glibenclamide $(0.001 \mathrm{ng} /$ eye twice at $48 \mathrm{~h}$ interval $)$ as compared to saline injection. Assuming a fold change $\geq 1.2$ and a $p$ value $\leq 0.05,300$ genes were up-regulated and 8 genes were down-regulated. Supplemental Table 2 shows the top 50 regulated genes in glibenclamide vs. $\mathrm{NaCl}$ injected retinas. Amongst the most significantly up-regulated genes, some encode proteins with known neuroprotective and anti-oxidant properties such as osteopontin (spp1), clusterin (Clu), lipocalin 2 (lcn2), Steap 4, Serpin g1, C1q, CD200R1, Bcl2a. Figure 7 shows a network and 2 dotplots of the pathways regulated by glibenclamide.

\section{Determination of ocular levels after oral administration of glibenclamide}

To evaluate the ocular levels of glibenclamide after oral administration at antidiabetic doses, we tested the oral glibenclamide suspension, Amglidia ${ }^{\circledR}$, in rats.

At the maximal human dose of $0.2 \mathrm{mg} / \mathrm{kg}$, a mean concentration of glibenclamide of 0.26 $\mathrm{ng} / \mathrm{mL}( \pm 0.04 \mathrm{ng} / \mathrm{mL})$ was measured in the ocular media after one hour, representing 10 times more than the minimal efficient retinal neuroprotective dose tested [Supplemental Fig. 8]. Retinal neuroprotective glibenclamide concentrations can thus be obtained either by direct intraocular injection, or by oral administration of low doses. Patients treated with glibenclamide at antidiabetic doses might thus get efficient neuroprotective ocular concentrations.

\section{DISCUSSION}

We have shown herein that the glibenclamide receptor SUR1 is expressed in the retina in 
rodents and in humans, and that glibenclamide (glyburide) exerts neuroprotective effects on the retina, avoiding cell death and preserving visual function through direct binding to its receptor SUR1. These data are consistent with reports showing that glibenclamide exerts neuroprotection in various models of cerebral and medullar injury. ${ }^{8,11,26-34}$ Indeed, SUR1 blockade with low-dose glibenclamide reduced cerebral edema, infarct volume, and mortality in mice by $50 \% .^{11}$ On the other hand, TRPM4 contributes to cerebral edema and its pharmacological inhibition by glibenclamide resulted in reduced axonal and neuronal degeneration and attenuated the severity of experimental autoimmune encephalomyelitis. ${ }^{35}$

Since no animal model recapitulates all the features of human diabetic retinopathy, we have used three complementary models to evaluate the potential of glibenclamide as a retinoprotective agent. The model of transient neonatal hyperglycaemia-induced retinopathy, reproduces common aspects of diabetic retinopathy and retinopathy of prematurity (neuronal cell death and inflammation, and inhibition of physiological angiogenesis) within a very short timeframe. ${ }^{18}$ In this model, oral administration, at non-hypoglycaemic dose, reduced the loss of ganglion cells and interneurons, demonstrating that the protective effect was not due to prevention of hyperglycaemia-induced damages but through direct effect of glibenclamide on retinal cells, that do express SUR1 as early as post-natal day 2. This result may have relevant significance as transient hyperglycaemia in extremely low birth weight infants is strongly associated with the occurrence of retinopathy of prematurity. ${ }^{36,37}$ Glibenclamide (a paediatric oral suspension named Amglidia ${ }^{\circledR}$ approved in Europe by the EMA) might thus be proposed not only to control transient hyperglycaemia but also to directly protect the retina. Further

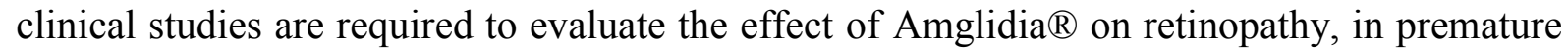
infants.

The NMDA-induced retinal excitotoxic model ${ }^{38,39}$ creates the conditions of high extracellular glutamate concentrations and subsequent neuroretinal cell death, via an apoptotic 
mechanism that has been observed in diabetic retinopathy and glaucoma. ${ }^{40}$ In this model, glibenclamide directly injected into the vitreous of adult rats, while not significantly affecting blood glucose, did protect the retinal function and structure, demonstrating that in adult, glibenclamide is also protective against excitotoxic stress. The GK rat model is a spontaneous non-obese and non-insulin dependent diabetes mellitus (type 2 diabetes) and a relevant model for human diabetic retinopathy. ${ }^{15,41}$ In this model, not only retinal function was improved, as shown by ERG improvement of the inner and outer retina activity, but intraocular glibenclamide also seemed to reduce the retinal swelling and outer retina morphology, potentially through its effect on retinal Müller glial cells. Using retina slices, gliclazide had direct effect on intracellular calcium changes induced by STZ, ${ }^{42}$ suggesting that glibenclamide could influence electroretinographic response by a direct effect on ion transport. In one limited study, gliclazide did not show superior effect as compared to insulin to reverse early signs of microangiopathy ${ }^{43}$ but no clinical study has been specifically designed to evaluate whether diabetic patients under glibenclamide had fewer retinopathy complications as compared to patients receiving other antidiabetic treatments.

SUR1 functions are associated with different ion channels depending on the target tissue. In insulin-secreting pancreatic cells, the ATP-sensitive potassium $\left(\mathrm{K}_{\mathrm{ATP}}\right)$ channel is composed of SUR1 and Kir6.2. ${ }^{44}$ In the brain, it remains controversial whether glibenclamide targets include the SUR1-regulated NC(Ca-ATP) $(\mathrm{SUR} 1 / \mathrm{TRPM} 4)$ channel. ${ }^{45}$ In contrast with brain cells and insulin-secreting cells, co-localization of TRPM4 and Kir6.2 was observed in the primate and human retinas, although the function of this pairing remains to be understood. The retinal glibenclamide effect induced by SUR1 binding probably occurs by modification of membrane polarization through cation (TRPM4) and potassium (Kir6.2) trans-membrane movements. However, in the rat retina, SUR1 does not co-localize completely with either TRPM4 or Kir6.2, suggesting that another channel is likely coupled with SUR1 for retinal 
neuroprotection, which should be further identified.

Interestingly, the effects of glibenclamide on the retina also resulted from transcriptional regulations of genes involved in neuroprotection and in the restoration of the blood retinal barrier. Amongst the most significantly up-regulated genes involved in neuroprotection, SPP1 encoding osteopontin was recently identified as major mediator of ganglion cell neuroprotection mediated by Müller glial cells. ${ }^{46} \mathrm{Clu}$ encoding clusterin was recently shown to protect against retinal cell death in model of retinitis pigmentosa through activation of Akt and STAT3, followed by Bax suppression. ${ }^{47}$ Interestingly, clusterin exerted protective effects in a rodent model of diabetic retinopathy induced by STZ, in which it improved both the retinal barriers and the ERG function. ${ }^{48}$ Lcn2, which encodes lipocalin 2, is involved in prosurvival responses during retinal cell stress, increasing immune response gene expression such as $\mathrm{Ccl}$, $\mathrm{Ccl} 2$, and $\mathrm{Cxcl10}$ and anti-oxidant molecules such as hemeoxygenase 1 and superoxide dismutase $2^{49}$ that were all up-regulated by glibenclamide. Other genes, encoding anti-oxidant proteins were up-regulated such as Steap4, ${ }^{50}$ PRDX4, transferrin 51,52 and ceruloplasmin, which protect against iron-mediated oxidative damage; and as glutaredoxin that protects human RPE cells from $\mathrm{H} 2 \mathrm{O} 2$ oxidative damage by preventing AKT glutathionylation. $^{53}$

Another potential important mechanism of action of glibenclamide could be the upregulation of $c d 200 r 1$, as its agonist CD200FC significantly protected ganglion cells from apoptosis in a nerve crush model. ${ }^{54}$ The up-regulation of $B c l 2 a l$ gene, with a strong antiapoptotic effect is in line with this hypothesis.

The role of macrophage/microglia in the effect of glibenclamide is suggested by the upregulation of P2RY12, a marker of microglia activation, shown to protect the photoreceptors in a model of retinal detachment. ${ }^{55}$ Importantly, P2RY12 is essential to permit the closure of the blood-brain barrier ${ }^{56}$ which could also contribute to the reduction of edema observed 
after glibenclamide administration in the GK rat. It can be hypothesized that glibenclamide directly regulates microglia in the retina via SUR1, which is expressed in microglia in inflammatory conditions. ${ }^{57}$ Glibenclamide treatment regulates many complement cascade molecules expression as serpin $\mathrm{gl}, \mathrm{Clqa}, \mathrm{Clqc}, \mathrm{Cl}, \mathrm{Clr}, \mathrm{C2}$, and $\mathrm{CFH}$. Other important genes, encoding proteins involved in the retinal barrier breakdown, cell death and apoptosis were down-regulated by glibenclamide such as, respectively, $V E G F-A$ and calpains. ${ }^{58}$ Interestingly, glibenclamide up-regulated the retinal neuroprotective factor $\mathrm{CNTF} .{ }^{59}$

The improvement of retinal function, observed after a short treatment period could be mostly explained by a change in retinal and Müller glial cell function, but longer treatment could also include prevention of cell death through the transcriptomic regulations.

In conclusion, we have demonstrated that glibenclamide acts as a neuroprotectant drug on the retina using various animal models that recapitulate mechanisms of neurodegeneration occurring in the human diabetic retina. Glibenclamide exerts this effect through direct interaction with SUR1 and potentially TRPM4 and Kir6.2 in retinal cells. In addition to the modulation of ion channels, we showed that glibenclamide influences the regulation of multiple genes in the neuroretina that contribute to its anti-apoptotic effects. The repurposing of known drugs, using specific ocular formulations, offers the advantage of a quicker clinical translation. Glibenclamide should be considered as one potential candidate for neuroprotection in diabetic patients.

\section{ACKNOWLEDGEMENTS}

The authors thank Dr John C. Saari (University of Washington, Seattle) for providing antibodies. This study was supported by the French Fondation de France, the association Centre de Recherche en Ophtalmologie (CRO)-Tous unis pour la Vision, the Aide aux Jeunes Diabétiques, the Société Francophone du Diabète and the French Agence Nationale de la 
Recherche (ANR-15-CE18-0032), which had no involvement in the studies. The guarantor is F.B.-C.

Conflict of interest statement. M.P. is scientific adviser for AMMTeK. All authors have read the journal's policy on disclosure of potential conflicts of interest.

All authors have read the journal's authorship agreement and that the manuscript has been reviewed by and approved by all named authors.

Author contributions. M.B., M.P., E.K.D., P.C., and F.B.-C. designed the study. M.B., K.D., M.C.N., E.P., L.R., A.D., L.R., J.C.J., E.K.D., and P.C. performed the experimental work. M.B., K.D., and P.C. performed and analysed retinal electrophysiology. M.B., M.P., K.D., E.K.D., P.C., and F.B.-C. analysed the data. A.M. and F.B.-C. collected human samples. M.B. and P.C. collected monkey samples. M.B., K.D., C.K., E.K.D., P.C., and F.B.-C. performed and interpreted confocal microscopy. M.B., K.D., M.C.N., E.K.D., and P.C. did immunohistochemistry. K.D., P.C., M.B., and F.B.-C. performed siRNA experiments. M.S. and L.J. performed semi-thin analysis. Z.D. and C.G. performed glibenclamide dosage in ocular media. J.G. performed the RNA sequencing analysis. M.B., M.P., J.B., E.K.D., P.C., and F.B.-C wrote the manuscript and all authors contributed to reviewing the manuscript. 


\section{REFERENCES}

1. Tao Z, Shi A, Zhao J. Epidemiological Perspectives of Diabetes. Cell Biochem Biophys 2015;73(1):181-5.

2. Panton UH, Bagger M, Barquera S. Projected diabetes prevalence and related costs in three North American urban centres (2015-2040). Public Health 2018;157:43-49.

3. Nentwich MM, Ulbig MW. Diabetic retinopathy - ocular complications of diabetes mellitus. World J Diabetes 2015;6 (3):489

4. Li Q, Zemel E, Miller B, Perlman I. Early retinal damage in experimental diabetes: electroretinographical and morphological observations. Exp Eye Res 2002;74 (5): 615

5. Tzekov R, Arden GB. The electroretinogram in diabetic retinopathy. Surv Ophthalmol 1999;44 (1): 53

6. Stem MS, Gardner TW. Neurodegeneration in the pathogenesis of diabetic retinopathy: molecular mechanisms and therapeutic implications. Curr Med Chem 2013;20 (26):3241

7. Sharma M, Nazareth I, Petersen I. Trends in incidence, prevalence and prescribing in type 2 diabetes mellitus between 2000 and 2013 in primary care: a retrospective cohort study. BMJ Open 2016;6(1), e010210

8. Kurland DB, Tosun C, Pampori A, et al. Glibenclamide for the treatment of acute CNS injury. Pharmaceuticals (Basel) 2013;6(10):1287

9. Kunte H, Busch MA, Trostdorf K. Hemorrhagic transformation of ischemic stroke in diabetics on sulfonylureas. Ann Neurol 2012;72 (5):799

10. Kunte H, Schmidt S, Eliasziw M. Sulfonylureas improve outcome in patients with type 2 diabetes and acute ischemic stroke. Stroke 2007;38(9):2526

11. Caffes N, Kurland DB, Gerzanich V, Simard JM. Glibenclamide for the treatment of ischemic and hemorrhagic stroke. Int J MolSci 2015;16 (3), 4973

12. Beltrand J, Elie C, Busiah K. Sulfonylurea Therapy Benefits Neurological and Psychomotor Functions in Patients With Neonatal Diabetes Owing to Potassium Channel Mutations. Diabetes Care 2015;38(11):2033

13. Delaunay K, Khamsy L, Kowalczuk L, et al. Glial cells of the human fovea. Mol Vis. 2020;26:235-245. Published 2020 Apr 1.

14. Crisanti P, Laplace O, Lecain E, Jonet L, Jeanny JC, Omri B. The role of PKCzeta in NMDA-induced retinal ganglion cell death: prevention by aspirin. Apoptosis 2006;11(6): 983

15. Kakizaki M, Masaki N. Spontaneous diabetes produced by selective breeding of normal Wistar rats. Proc. Jpn. Acad 1975;51

16. Omri S, Behar-Cohen F, Rothschild PR, et al. PKCzeta mediates breakdown of outer blood-retinal barriers in diabetic retinopathy. PLoS One 2013;8(11),e81600

17. Omri S, Behar-Cohen F, de Kozak Y, et al. Microglia/macrophages migrate through retinal epithelium barrier by a transcellular route in diabetic retinopathy: role of PKCzeta in the Goto Kakizaki rat model. Am J Pathol 2011;179(2):942

18. Kermorvant-Duchemin E, Pinel AC, Lavalette S, et al. Neonatal hyperglycemia inhibits angiogenesis and induces inflammation and neuronal degeneration in the retina. PLoS One 2013;8(11),e79545

19. Dobin A, Davis CA, Schlesinger F, et al. "STAR: ultrafast universal RNA-seq aligner." Bioinformatics 2013;29.1: 15-21

20. Li B, Dewey CN. "RSEM: accurate transcript quantification from RNA-Seq data with or without a reference genome." BMC bioinformatics 2011;12.1: 323

21. Robinson MD, McCarthy DJ, Smyth GK. "edgeR: a Bioconductor package for differential expression analysis of digital gene expression data." Bioinformatics 2010;26.1:139-140. 
22. Simard J, Chen M, Tarasov K, et al. Newly expressed SUR1-regulated NC(Ca-ATP) channel mediates cerebral edema after ischemic stroke. Nat Med 2006;12 (4):433.

23. Rothschild P, Salah S, Berdugo M, et al. ROCK-1 mediates diabetes-induced retinal pigment epithelial and endothelial cell blebbing: Contribution to diabetic retinopathy. Sci Rep 2017;7(1):8834

24. Miyamoto K, Ogura $\mathrm{Y}$, Nishiwaki $\mathrm{H}$, et al. Evaluation of retinal microcirculatory alterations in the Goto-Kakizaki rat. A spontaneous model of non-insulin-dependent diabetes. Invest Ophthalmol Vis Sci 1996;37(5):898

25. Jonsson KB, Frydkjaer-Olsen U, Grauslund J. Vascular Changes and Neurodegeneration in the Early Stages of Diabetic Retinopathy: Which Comes First? Ophthalmic Res 2016;56:1-9

26. Simard JM, Tsymbalyuk O, Ivanov A, et al. Endothelial sulfonylurea receptor 1-regulated NC Ca-ATP channels mediate progressive hemorrhagic necrosis following spinal cord injury. J Clin Invest 2007;117(8):2105

27. Simard JM, Geng Z, Woo SK, et al. Glibenclamide reduces inflammation, vasogenic edema, and caspase-3 activation after subarachnoid hemorrhage. J Cereb Blood Flow Metab 2009;29(2):317

28. Simard JM, Popovich PG, Tsymbalyuk O, et al. MRI evidence that glibenclamide reduces acute lesion expansion in a rat model of spinal cord injury. Spinal Cord 2013;51(11):823

29. Simard JM, Popovich PG, Tsymbalyuk O, Gerzanich V. Spinal cord injury with unilateral versus bilateral primary hemorrhage--effects of glibenclamide. Exp Neurol 2012;233(2):829

30. Simard JM, Sheth KN, Kimberly WT, et al. Glibenclamide in cerebral ischemia and stroke. Neurocrit Care 2014;20(2):319

31. Simard JM, Tsymbalyuk O, Keledjian K, Ivanov A, Ivanova S, Gerzanich V. Comparative effects of glibenclamide and riluzole in a rat model of severe cervical spinal cord injury. Exp Neurol 2012;233(1):566

32. Simard JM, Woo SK, Tsymbalyuk N, et al. Glibenclamide-10-h Treatment Window in a Clinically Relevant Model of Stroke. Transl Stroke Res 2012;3(2):286

33. Simard JM, Yurovsky V, Tsymbalyuk N, Melnichenko L, Ivanova S, Gerzanich V. Protective effect of delayed treatment with low-dose glibenclamide in three models of ischemic stroke. Stroke 2009;40(2):604

34. Tosun C, Koltz MT, Kurland DB, et al. The protective effect of glibenclamide in a model of hemorrhagic encephalopathy of prematurity. Brain Sci 2013;3(1):215

35. Schattling B, Steinbach K, Thies E, Kruse M, Menigoz A, Ufer F. TRPM4 cation channel mediates axonal and neuronal degeneration in experimental autoimmune encephalomyelitis and multiple sclerosis. Nat Med 2012;18(12):1805

36. Garg R, Agthe AG, Donohue PK, Lehmann CU. Hyperglycemia and retinopathy of prematurity in very low birth weight infants. J Perinatol 2003;23(3):186

37. Mohsen L, Abou-Alam M, El-Dib M, Labib M, Elsada M, Aly H. A prospective study on hyperglycemia and retinopathy of prematurity. J Perinatol 2014;34(6):453

38. Luan H, Roberts R, Sniegowski M, Goebel DJ, Berkowitz BA. Retinal thickness and subnormal retinal oxygenation response in experimental diabetic retinopathy. Invest Ophthalmol Vis Sci 2006;47(1):320

39. Al-Gayyar MM, Abdelsaid MA, Matragoon S, Pillai BA, El-Remessy AB. Neurovascular protective effect of FeTPPs in N-methyl-D-aspartate model: similarities to diabetes [published correction appears in Am J Pathol 2015;185(6):1795-6]. Am J Pathol 2010;177(3):1187-1197

40. Omri S, Omri B, Savoldelli $\mathrm{M}$, et al. The outer limiting membrane (OLM) revisited: clinical implications. Clin Ophthalmol 2010;4:183-195. 
41. Gong CY, Lu B, Sheng YC, Yu ZY, Zhou JY, Ji LL. The Development of Diabetic Retinopathy in Goto-Kakizaki Rat and the Expression of Angiogenesis-Related Signals. Chin J Physiol 2016;59 (2):100

42. Kinukawa J, Shimura M, Harata N, Tamai M. Gliclazide attenuates the intracellular Ca2+ changes induced in vitro by ischemia in the retinal slices of rats with streptozotocininduced diabetes. Curr Eye Res 2005;30(9):789-98

43. Jerums G, Murray RM, Seeman E et al. Lack of effect of gliclazide on early diabetic nephropathy and retinopathy: a two-year controlled study. Diabetes Res Clin Pract 1987;3(2):71-80

44. Babenko AP, Polak M, Cavé H, et al. Activating mutations in the ABCC8 gene in neonatal diabetes mellitus. N Engl J Med 2006;355(5):456

45. Walcott BP, Kahle KT, Simard JM. Novel treatment targets for cerebral edema. Neurotherapeutics 2012;9(1):65

46. Ruzafa N, Pereiro X, Lepper MF, Hauck SM, Vecino E. Proteomics Approach to Identify Candidate Proteins Secreted by Müller Glia that Protect Ganglion Cells in the Retina. Proteomics 2018;18(11):e1700321

47. Vargas A, Kim HS, Baral E, Yu WQ, Craft CM1, Lee EJ. Protective effect of clusterin on rod photoreceptor in rat model of retinitis pigmentosa. PLoS One 2017;12(8):e0182389

48. Zhang $\mathrm{C}$, Nie J, Feng L et al. The emerging roles of clusterin on reduction of both blood retina barrier breakdown and neural retina damage in diabetic retinopathy. Discov Med 2016;21(116):227-37

49. Parmar T, Parmar VM, Perusek L, et al. Lipocalin 2 Plays an Important Role in Regulating Inflammation in Retinal Degeneration. J Immunol. 2018;200(9):3128-3141.

50. Zhou J, Ye S, Fujiwara T, Manolagas SC, Zhao H. Steap4 plays a critical role in osteoclastogenesis in vitro by regulating cellular iron/reactive oxygen species (ROS) levels and cAMP response element-binding protein (CREB) activation. J. Biol. Chem 2013;288:30064-30074

51. Picard E, Fontaine I, Jonet L, et al. The protective role of transferrin in Muller glial cells after iron-induced toxicity. Mol Vis 2008;14:928-941

52. Picard E, Le Rouzic Q, Oudar A, et al. Targeting iron-mediated retinal degeneration by local delivery of transferrin. Free Radic Biol Med 2015;89:1105-1121.

53. Liu X, Jann J, Xavier C, Wu H. Glutaredoxin 1 (Grx1) Protects Human Retinal Pigment Epithelial Cells From Oxidative Damage by Preventing AKT Glutathionylation. Invest Ophthalmol Vis Sci 2015;56, 2821-2832

54. Huang R, Lan Q, Chen L, et al. CD200Fc Attenuates Retinal Glial Responses and RGCs Apoptosis After Optic Nerve Crush by Modulating CD200/CD200R1 Interaction. J. Mol. Neurosci. MN 2018;64:200-210

55. Okunuki Y, Mukai R, Pearsall EA et al. Microglia inhibit photoreceptor cell death and regulate immune cell infiltration in response to retinal detachment. ProcNatlAcadSci U S A 2018;3;115(27):E6264-E6273

56. Lou N, Takano T, Pei Y, Xavier AL, Goldman SA, NedergaardM. Purinergic receptor P2RY12-dependent microglial closure of the injured blood-brainbarrier. ProcNatlAcadSci U SA 2016;26;113(4):1074-9

57. Kurland DB, Gerzanich V, Karimy JK et al. The Sur1-Trpm4 channel regulates NOS2 transcription in TLR4-activated microglia.J Neuroinflammation 2016;13(1):130

58. Nakajima E, David LL, Bystrom C, Shearer TR, Azuma M. Calpain-specific proteolysis in primate retina: Contribution of calpains in cell death. Invest Ophthalmol Vis Sci 2006; 47:5469-5475

59. Wen R, Tao W, Li Y, Sieving PA. CNTF and retina. Prog Retin Eye Res 2012;31:136-151 


\section{Figure legends}

Fig 1. SUR1 expression in human macular, foveal, and peripheral retina. Immunohistofluorescence and confocal microscope pictures. SUR1 (green) and glutamine synthetase (GS, red, located in the Müller glial cells and astrocytes) staining in sections of macula (A) and peripheral human retina (B) and co-labelling of SUR1 with cones markers (C). Blue $=$ DAPI. Bar $=50 \mu \mathrm{m}$. GCL $=$ Ganglion Cell Layer, IPL $=$ inner plexiform (synapses) layer. $\mathrm{INL}=$ inner nuclear layer of the bipolar neurons, OPL $=$ outer plexiform layer, $\mathrm{ONL}=$ outer nuclear layer of the photoreceptor neurons, OLM $=$ outer limiting membrane, IS/OS = outer and inner segments of photoreceptors.

\section{Figure 2 legend:}

Fig 2. Human macular expression of SUR1, TRPM4 and Kir6.2. SUR1 (green), TRPM4 (red) and Kir6.2 (red) staining in sections of human macula.

$\mathbf{A}$ and $\mathbf{B}$ : inner retina sections, $\mathbf{C}$ outer retina sections. White arrows show the cones.

$\mathrm{GCL}=$ Ganglion cell layer; $\mathrm{NFL}=$ nerve fibre layer; $\mathrm{INL}=$ inner nuclear layer; $\mathrm{ONL}=$ outer nuclear layer, $\mathrm{OLM}=$ outer limiting membrane. Bars $=50 \mu \mathrm{m}$.

\section{Figure 3 legend:}

Fig 3. SUR1, glutamine synthetase (GS), peanut agglutinin, TRPM4, and Kir6.2 immunolocalization in monkey retina. A: Flat-mounted monkey macula showing enrichment in Müller glial cells stained with glutamine synthetase (red) and in cones, stained with peanut agglutinin (green). B: Immunolocalization of SUR1 and GS on flat-mounted monkey macula showing SUR1 enrichment in the macula and co-staining with GS at the rim of the foveal pit and inside the pit (star). Bars $=100 \mu \mathrm{m} . \mathbf{C}$ : Immunohistochemistry of flat-mounted monkey retina with SUR1 (green), and either TRPM4 or Kir6.2 (red) at the ganglion cell layer (GCL) 
level or at the outer limiting membrane $(\mathrm{OLM})$ level. Bars $=20 \mu \mathrm{m} . \mathrm{GCL}=$ Ganglion Cell Layer. OLM = Outer Limiting Membrane.

\section{Figure 4 legend:}

Fig 4. Intravitreal glibenclamide (glyburide) injections provide retinal functional neuroprotection in case of NMDA-induced excitotoxicity or hyperglycaemia, in 6-weeks old Wistar rats. A-F: at $\mathrm{T}=24 \mathrm{~h}, \mathrm{NMDA}$-induced changes of electrical retinal responses $(\mathbf{A}-\mathbf{D}$ : amplitude reduction) to achromatic flash stimuli. A-B: responses recorded in scotopic conditions (essentially rod-driven responses) with increasing stimulus intensities, 0.0003 to $10 \mathrm{~cd} . \mathrm{s} / \mathrm{m}^{2}$. C-D: responses recorded in mesopic conditions (whole retina i.e both rod- and cone-driven, also called mixed responses). A: Scotopic b-wave amplitude variation (mostly generated by the rod-dependent inner retina, with participation of the cone-dependent inner retina at high stimulus intensities) in rats intraocularly injected with NMDA and treated by various doses of glibenclamide. NMDA induces rod-dependent internal retina function alterations (ANOVA $\mathrm{P}<0.0001$; Bonferroni post-test: *** $P<0.001 ; * * P<0.01 ;{ }^{*} P<0.05$ vs. NMDA).B: Variation in scotopic b-wave amplitudes in rats intraocularly injected with NMDA and pretreated with glibenclamide 5 days before (prevention) (ANOVA $\mathrm{P}<0.0001$; Bonferroni post-test: $* * * P<0.001 ; * * P<0.01 ; * P<0.05$ vs. NMDA). C: Variation of mesopic rod/cones also called mixed-driven inner retina response: variation in b-wave amplitudes in rats intraocularly injected with NMDA and treated by various doses of glibenclamide (Kruskal-Wallis test $P=0.0038$; Dunn's test: ${ }^{*} P<0.05$, $* * P<0.01$ vs. NMDA). D: Variation of mesopic rod/cones-driven inner retina response: variation in b-wave amplitudes in rats intraocularly injected with NMDA and pretreated with glibenclamide 5 days before (prevention) (Kruskal-Wallis test $P=0.0016$; Dunn's test: $* P<0.05$, $* * P<0.01$ vs. NMDA). Color codes for $A-F$ : blue = vehicle, $n o$ NMDA $(n=6)$; red $=\operatorname{NMDA}(n=6)$; green $=N M D A+0.001$ ng glibenclamide $(n=6) ;$ light grey $=N M D A+0.01$ ng glibenclamide 
$(n=6) ;$ dark grey $=N M D A+1 n g$ glibenclamide $(n=4) ;$ black $=N M D A+$ preventive $100 n g$ glibenclamide injection 5 days before $\operatorname{NMDA}(n=8)$. $\mathbf{E}-\mathbf{F}$ : Superposition of ERG registered curves. G-L: Glibenclamide-induced protection of electroretinogram in elderly (20-months old) diabetic Goto-Kakizaki (GK) rats treated by 3 intravitreal injections of $0.001 \mathrm{ng}$ glibenclamide vs vehicle. Mann-Whitney test was performed. G: Reduction (=improvement) of mixed rod-cone b-wave implicit times $(* P=0.03)$ in $0.001 \mathrm{ng}$ glibenclamide-treated GK rats as compared to vehicle-treated ones; H: Reduction of scotopic (rod) b-wave implicit times following blue flashes $(* * P=0.002)$; $\mathbf{I}$ : Reduction of scotopic (rod) b-wave implicit times with a 0.03 cd.s. $\mathrm{m}^{-2}$ white light stimulus $(* * P=0.002)$; J-K: Superposition of curves extracted from $\mathrm{G}$ histogram. L: Reduced lengthening of the blue a-wave implicit time by 0.001 ng glibenclamide treatment. Color codes for G-L: red lines and histograms: diabetic rat+vehicle treatment $(n=12)$; purple lines and purple/green histograms: diabetic rat +0.001 $n g$ glibenclamide treatment $(n=8)$

\section{Figure 5 legend:}

Fig 5. Glibenclamide treatment induces histological retinal neuroprotection. A: In hyperglycaemic rat neonates: retinal paraffin sections (toluidine blue staining) at PN14 of an untreated normoglycaemic rat (A a), an untreated streptozotocin-induced hyperglycaemic rat (A b), and a hyperglycaemic glibenclamide-treated rat (A c). NFL: nerve fibre layer; GCL: ganglion cells layer (red arrows); IPL: inner plexiform layer; INL: inner nuclear layer; OPL: outer plexiform layer; ONL: outer retinal layer; OLM: outer limiting membrane; IS: inner photoreceptor segments; OS: outer photoreceptor segments; RPE: retinal pigment epithelium; CHOR: choroid. B: Live retinal ganglion cell nuclei counting in the same neonate groups, performed on histological sections at post-natal day $14(\mathrm{PN} 14)(\mathrm{n}=5,8$ and 9 respectively, Kruskal-Wallis and Dunn's tests: $\left.{ }^{*} P<0,05\right)$. C: In elderly (20-months old) diabetic Goto- 
Kakizaki (GK) rat retinas: semi-thin sections from vehicle-treated rats, or $0.001 \mathrm{ng}$ glibenclamide-treated rats (3 intravitreal injections every other day) showing disorganized neuroretina, Müller cell swelling (yellow arrows), retinal pigment epithelium swelling (not shown), damage and vacuolization of rod segments (red star), and choroidal vasodilatation (not shown). Intraocular $0.001 \mathrm{ng}$ glibenclamide seemed to reduce the swelling of the Müller cells, to improve the alignment of the photoreceptor segments and to reduce the retinal pigment epithelium swelling, supporting an anti-edematous effect. D: NMDA-induced retinal apoptosis 24 hours after intravitreal injection of NMDA, in 6-weeks old Wistar rats. TUNEL+ apoptotic retinal cell counting in: (D a) naïve vs. NMDA-treated groups $(n=15$ and 16 respectively, Mann-Whitney test: $P<0.0001)$; $(\mathrm{D}$ b) vehicle-treated $(\mathrm{n}=16)$ vs. $0.01 \mathrm{ng}$ glibenclamide-treated $(n=14)$ vs. 1 ng glibenclamide-treated groups $(n=16)$. Concomitant injection of $1 \mathrm{ng}$ or $0.01 \mathrm{ng}$ glibenclamide per eye induced a significant reduction of $44.25 \%$ and $47.1 \%$ in retinal apoptotic cell death, respectively (Kruskal-Wallis $\mathrm{P}=0.0146$; multiple comparison Dunn's test: $1 \mathrm{ng}$ glibenclamide vs. NMDA alone: $40.23 \pm 4.04 / 22.43 \pm 4.25$, $\mathrm{P}<0.05 ; 0.01 \mathrm{ng}$ glibenclamide vs. NMDA alone: $21.3 \pm 4.7 /$ eye, $\mathrm{P}<0.05)$. (D c) vehicletreated $(\mathrm{n}=16)$ vs. $100 \mu \mathrm{g}$ glibenclamide-treated $(\mathrm{n}=8)$ vs. $100 \mathrm{ng}$ glibenclamide-treated groups $(\mathrm{n}=16), 5$ days before NMDA injection (prevention groups). Reductions of $77.1 \%$ and $87.1 \%$ in retinal apoptotic cell death with glibenclamide $100 \mu \mathrm{g}$ or 100-ng/eye, respectively $(10.07 \pm 2.87$ or $5.95 \pm 0.75$ TUNEL positive cells/eye vs. NMDA+vehicle; Kruskal-Wallis: $\mathrm{P}<0.0001$; Dunn's test $* * * P<0,001$ vs. NMDA alone). Bars $=10 \mu \mathrm{m}$ in A, $200 \mu \mathrm{m}$ in $\mathrm{C} \mathrm{a}-\mathrm{b}$; and $25 \mu \mathrm{m}$ in $\mathrm{C} \mathrm{c}-\mathrm{f}$.

\section{Figure 6 legend:}

Fig 6. Retinal immunohistochemical expression of SUR1, TRPM4, and Kir6.2 in the rat.

A: Normal rat, B: NMDA model (at 24 hours), C: One year old GK rat. 
SUR1 immunohistochemistry (green) on retinal sections of normal (A), NMDA (B) and GK rat (C) were co-stained with the Müller glial cell marker GS (red); and with DAPI for nuclei staining (blue). SUR1 staining increased in the GCL in NMDA and GK conditions, in the ONL and RMG cells in the NMDA conditions (B arrows) and at the OLM in the GK model $(\mathrm{C}$, arrows) $\mathrm{Bars}=50 \mu \mathrm{m} . \mathrm{GCL}=$ ganglion cell layer, $\mathrm{INL}=$ inner nuclear layer, $\mathrm{ONL}=$ outer nuclear layer, $\mathrm{OLM}=$ outer limiting membrane.

Immunohistochemistry of SUR1 (green) and either TRPM4 or Kir6.2 (red) was performed on flat-mounted retinas and imaged at the GCL level (right panel of A, B and C). Bar $=20 \mu \mathrm{m}$. SUR1 co-localized partly with TRPM4 that stains astrocytes and with Kir6.2 in ganglion cells and inner nuclear cells. Bars $=10 \mu \mathrm{m}$

\section{Figure 7 legend:}

Fig 7. RNA sequencing of neuroretinas from 1-year-old diabetic Goto-Kakizaki rats treated with 2 intravitreal injections at 48 hours interval of Glibenclamide $(0.001 \mathrm{ng} / \mathrm{eye} ; \mathrm{n}=3)$ vs. Vehicle (n=3). A: Cnetplot of dysregulated Wikipathways in Glibenclamide- vs. Vehicletreated diabetic GK rat retinas. It depicts the linkages of genes (bluescale) and biological concepts as a network. B: Dotplot of dysregulated pathways in Hallmark pathways in Glibenclamide- vs. Vehicle-treated 20-months old diabetic GK rat retinas. C: Dotplot of dysregulated pathways in Wikipathways in Glibenclamide- vs. Vehicle-treated 20-months old diabetic GK rat retinas. 


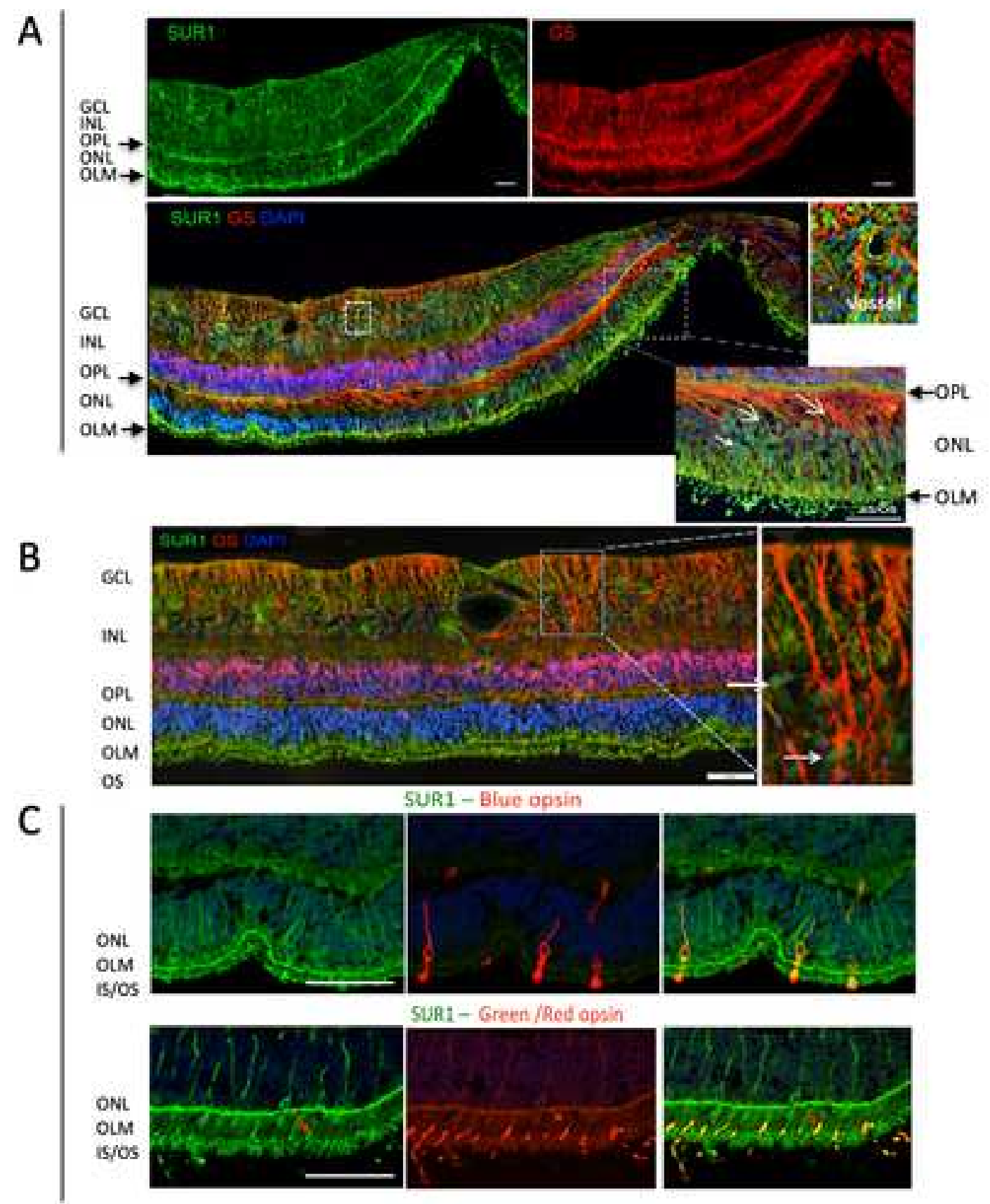

Figure 1 


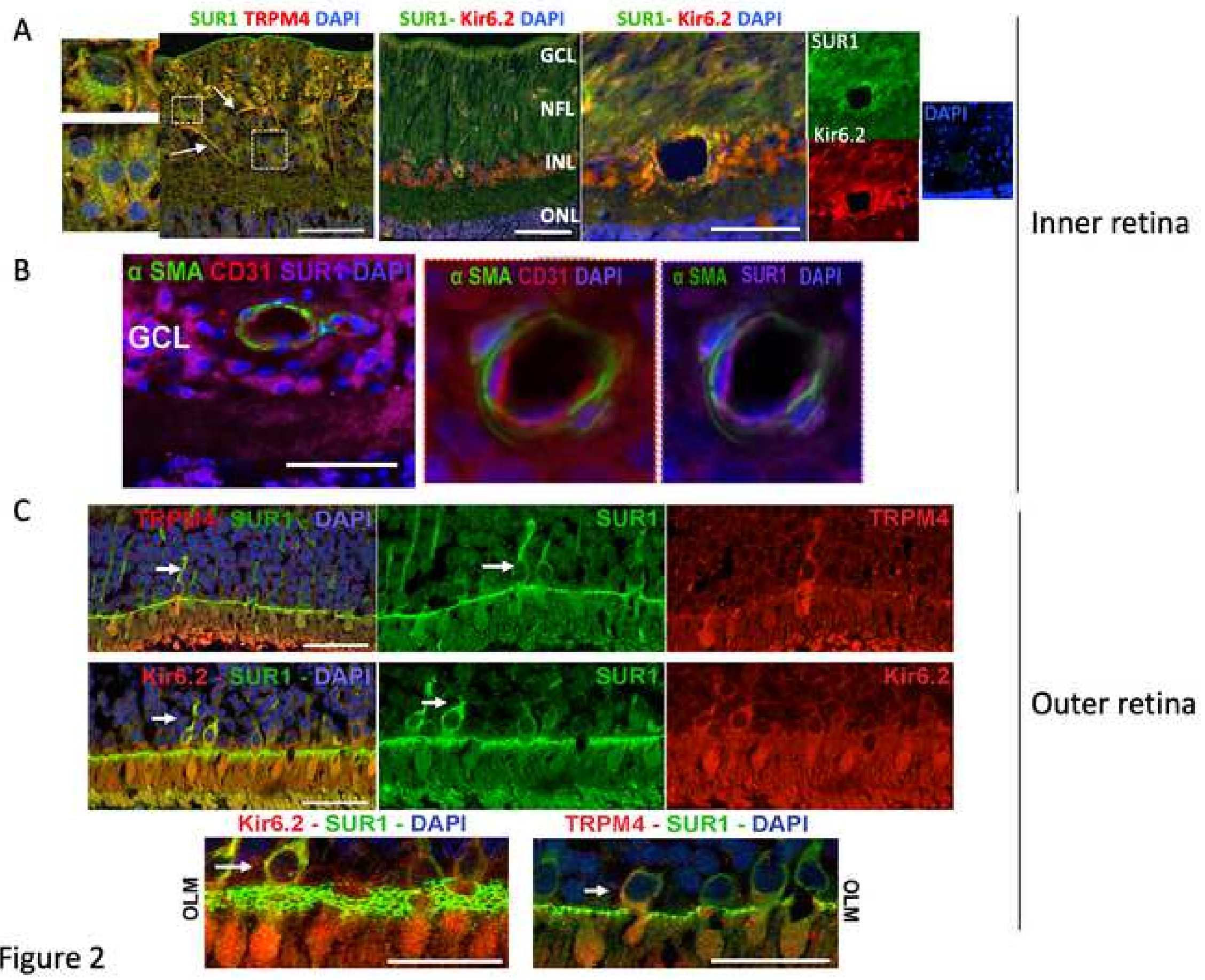




\section{A}

B

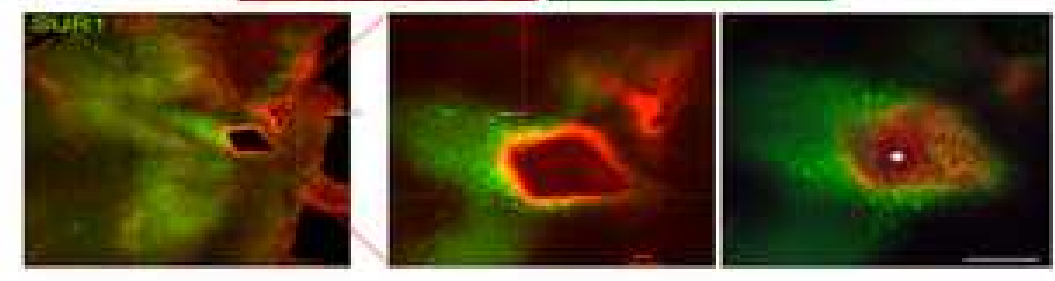

GCL

OLM

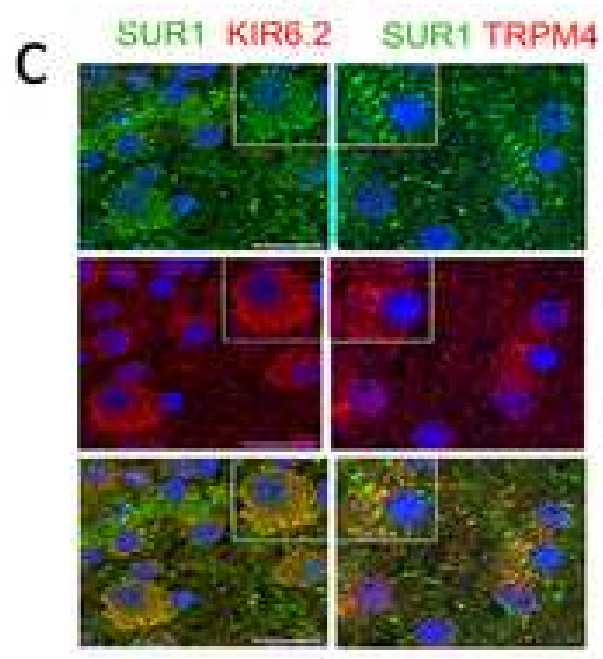

SUR1 KIR6.2 SUR1 TRPMA

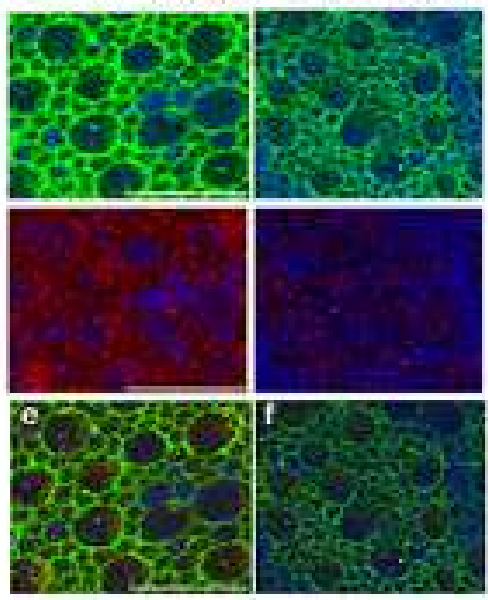

Figure 3 


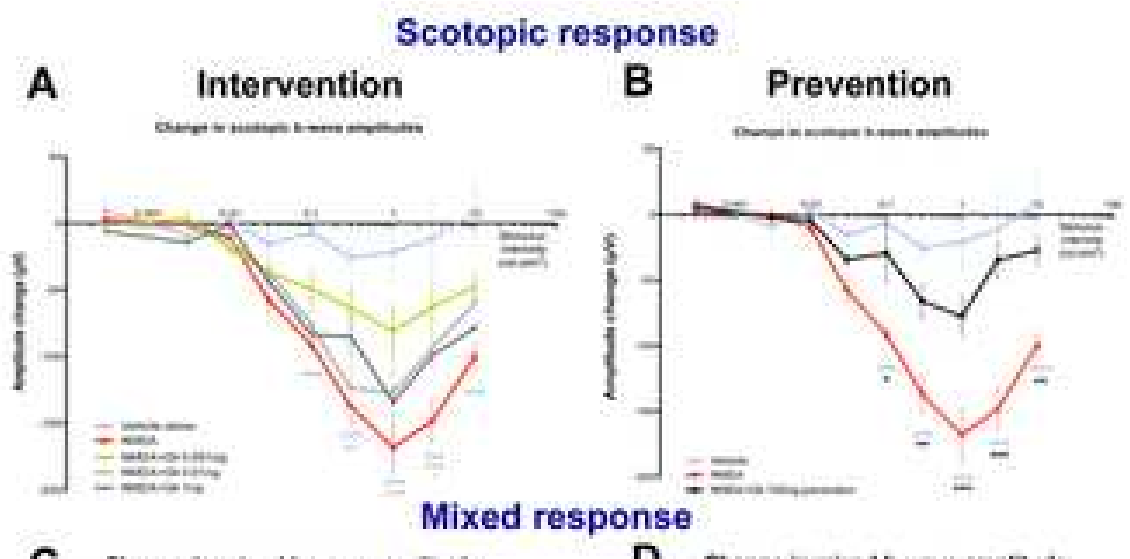

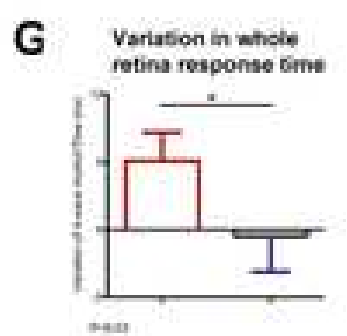

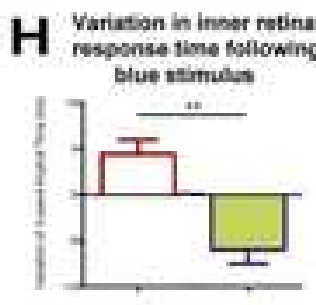

ine

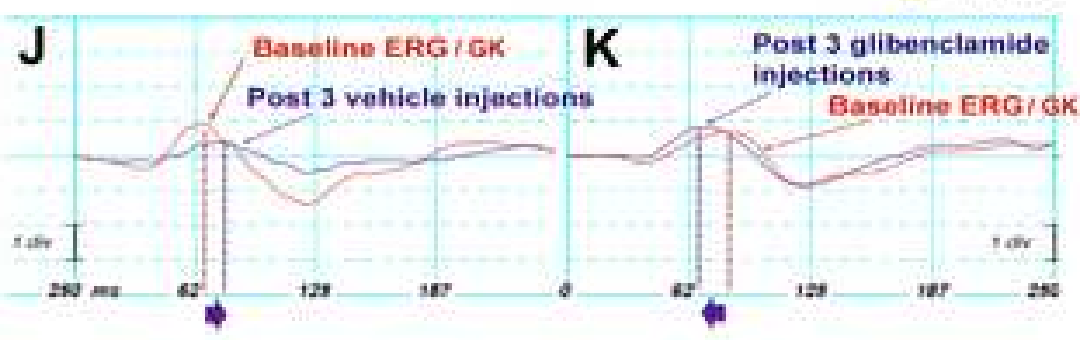

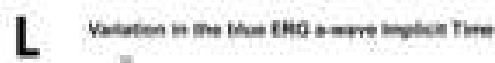
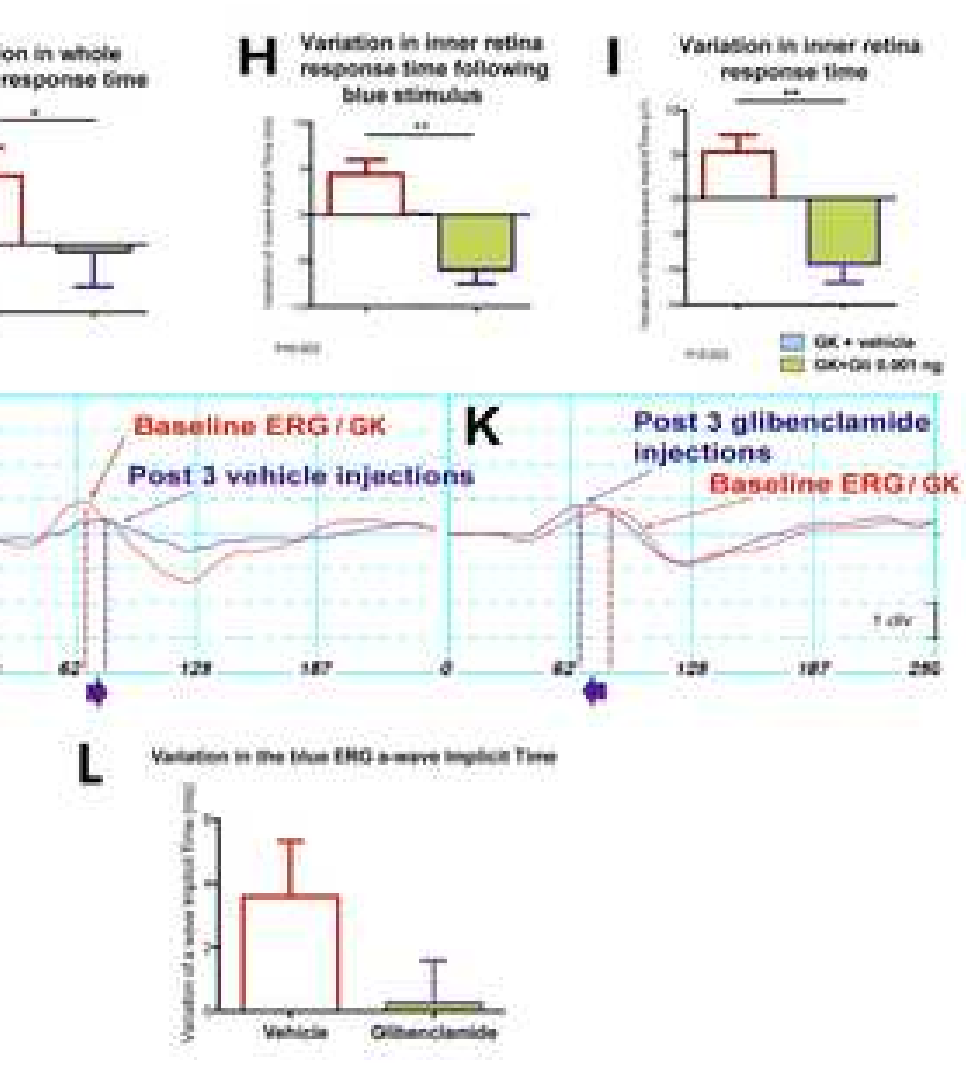

\section{Figure 4}
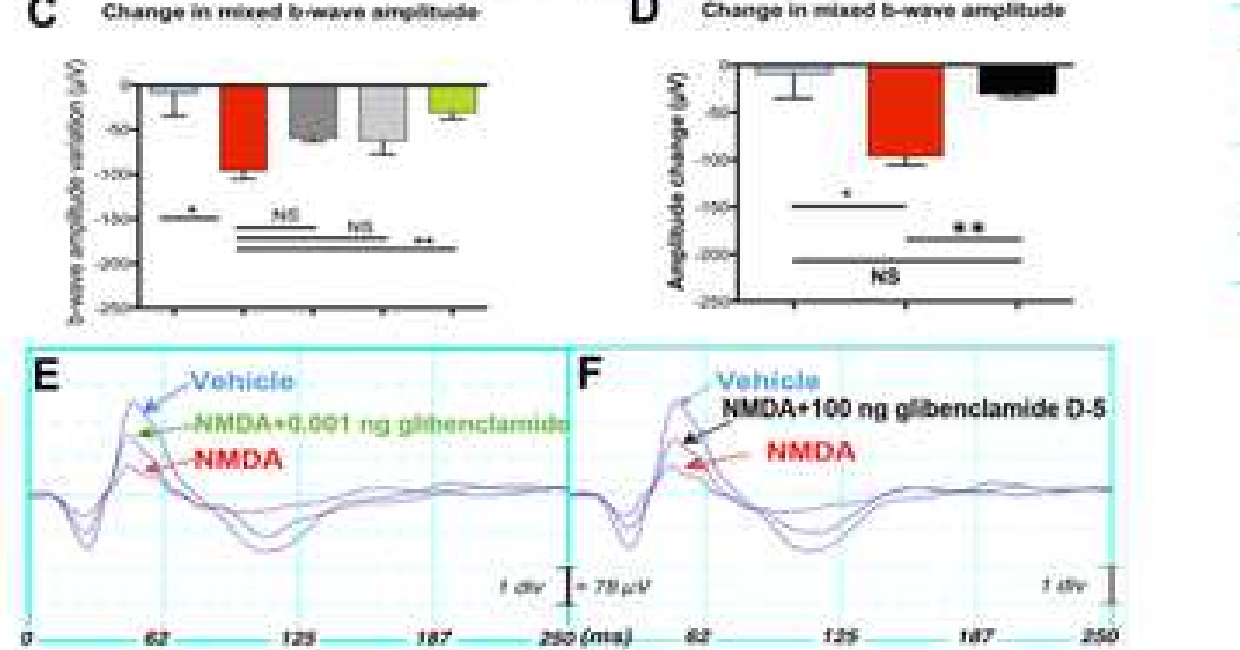


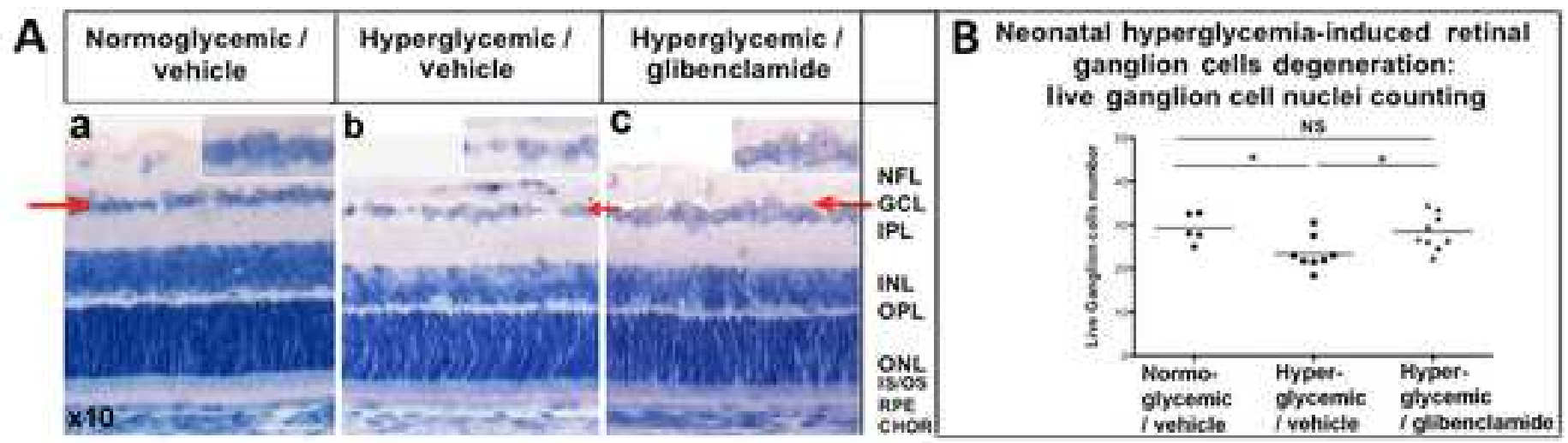

C

Diabetic GK rat / vehicle
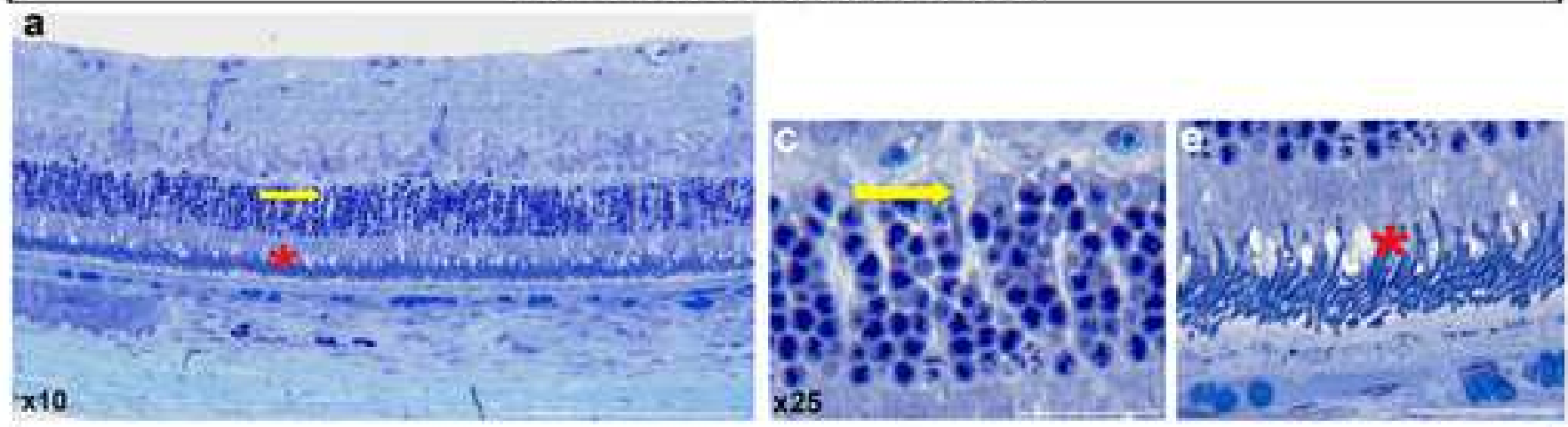

\section{Diabetic GK rat / Glibenclamide}

b
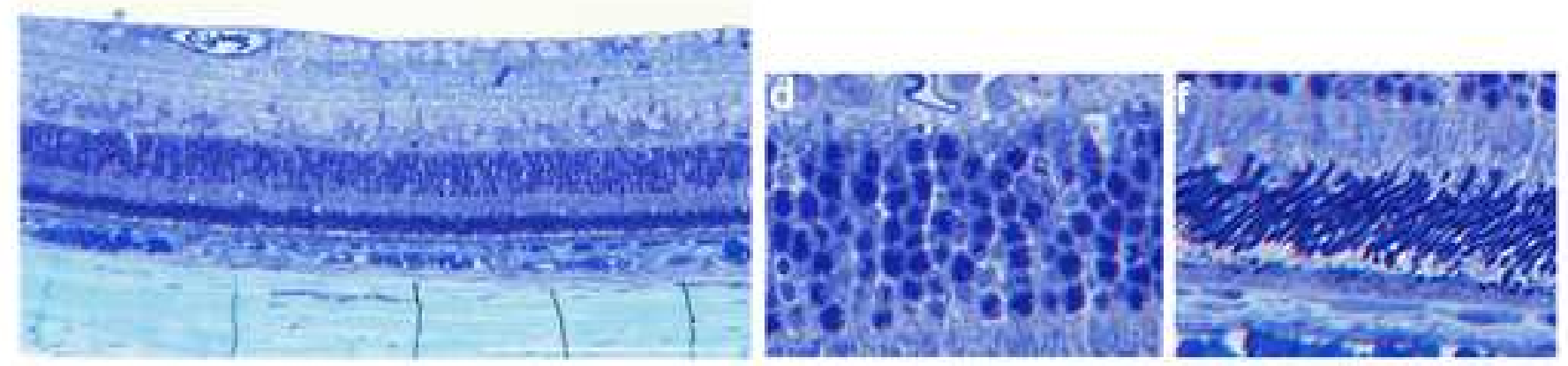

D

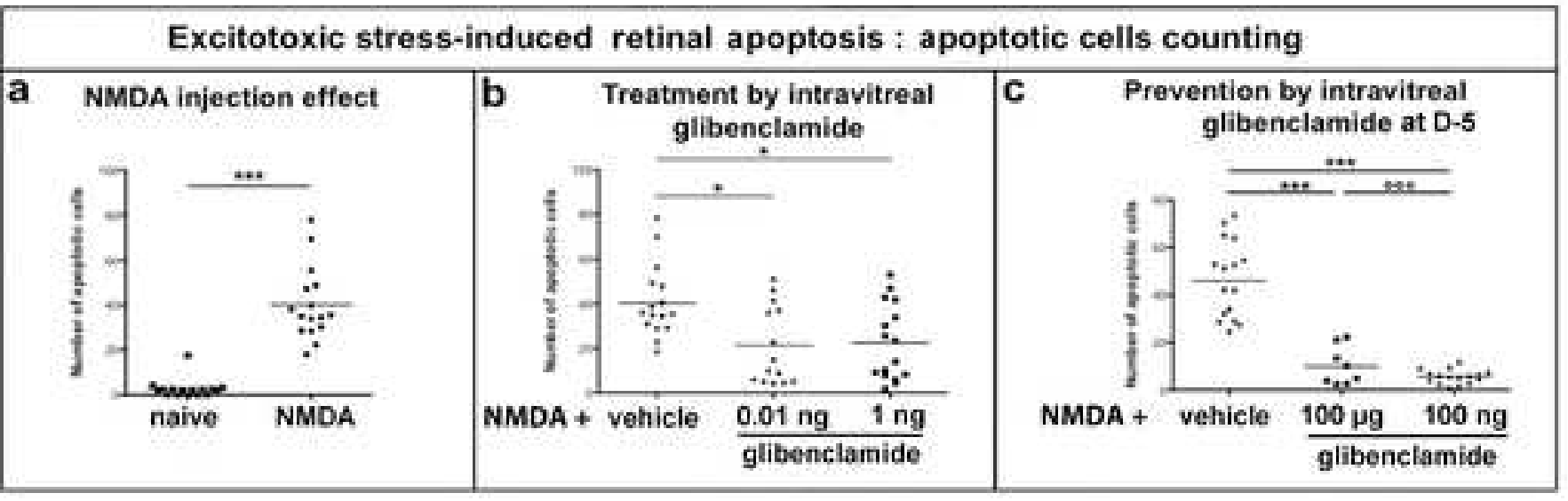


Sur1-dapi

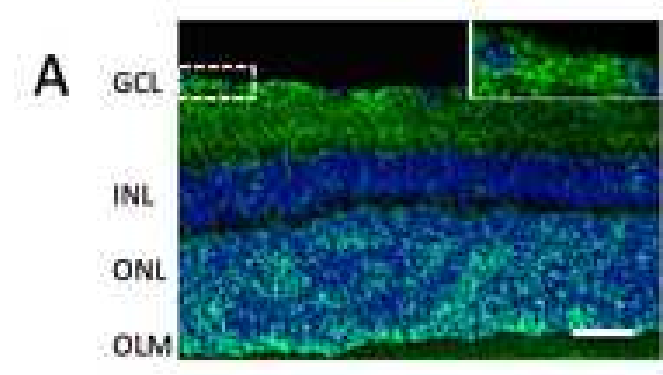

B

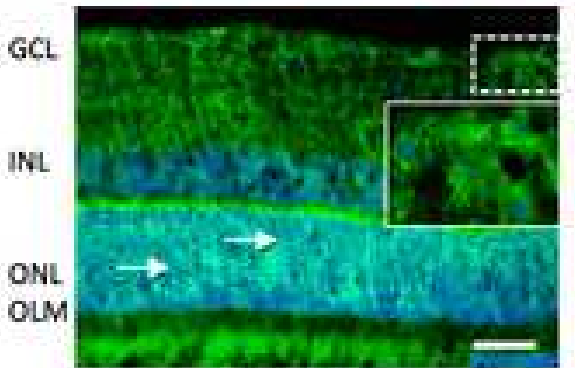

c

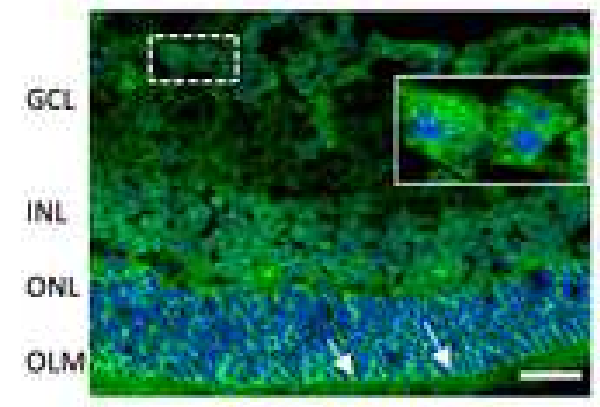

Sur1-GS
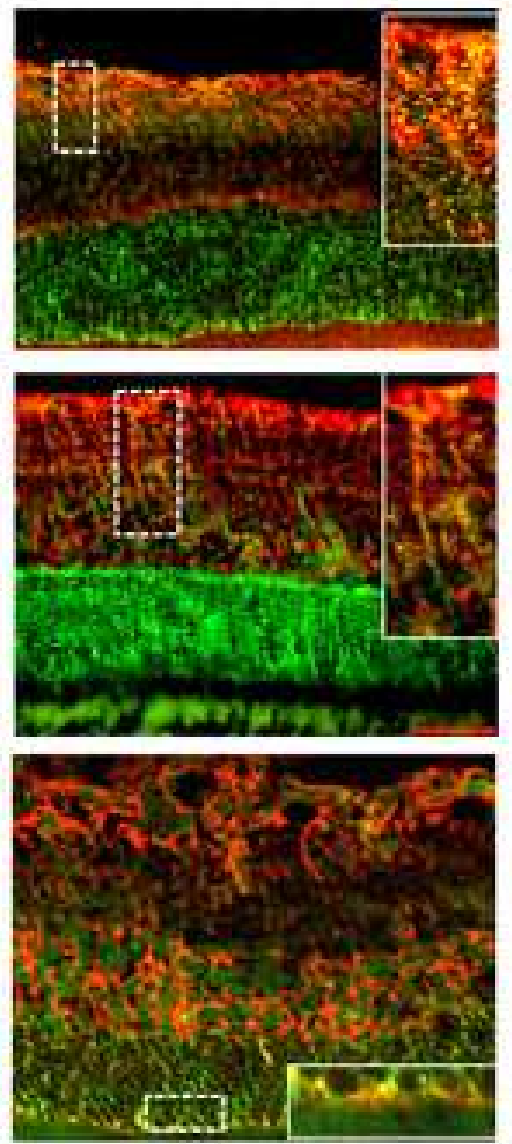

GCL «

Sur1-trpm4-dapi
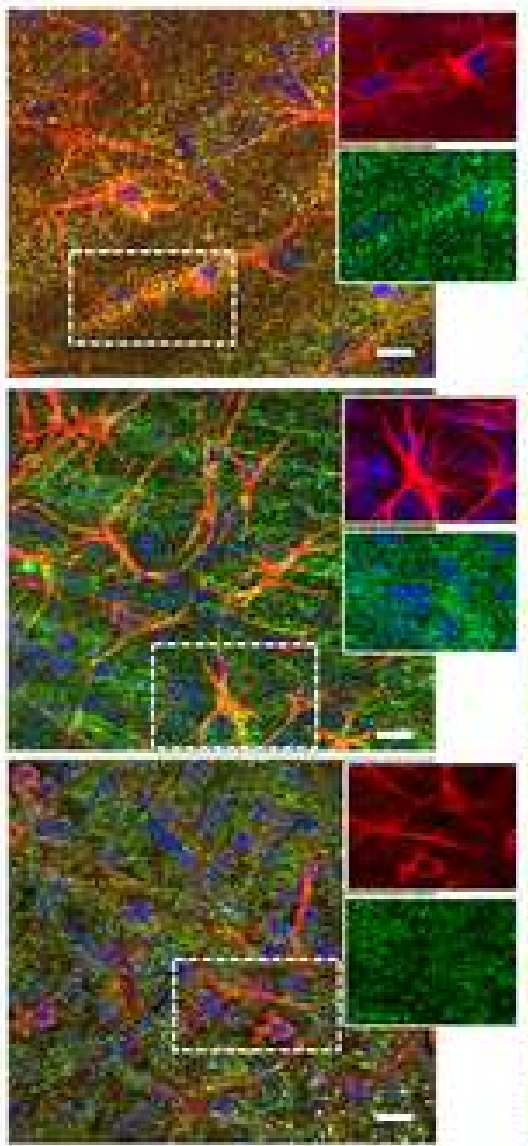

Sur1-KIR6.2-dapi
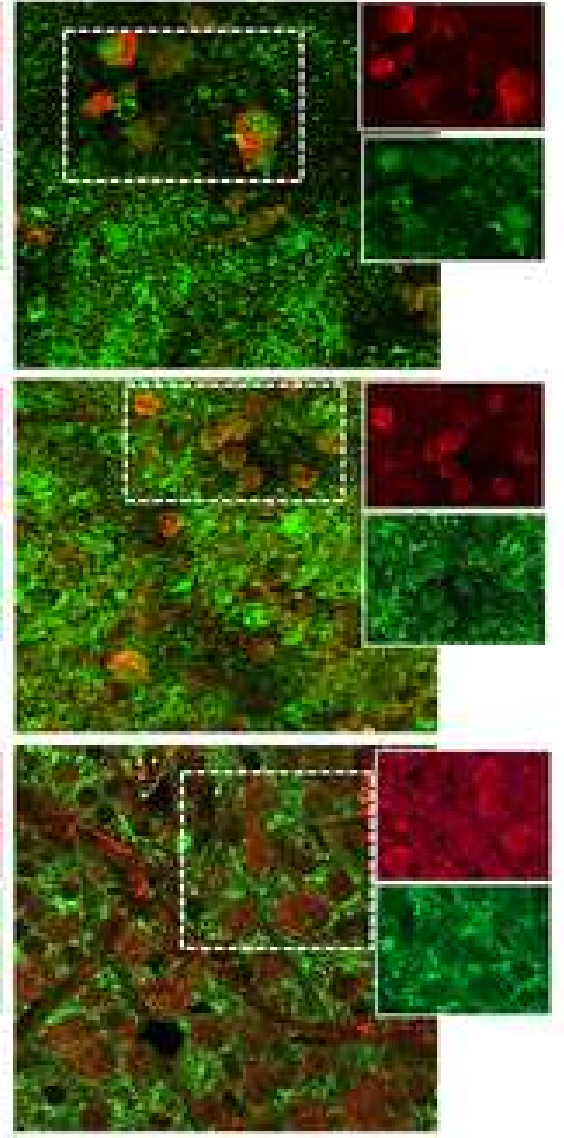

Figure 6 

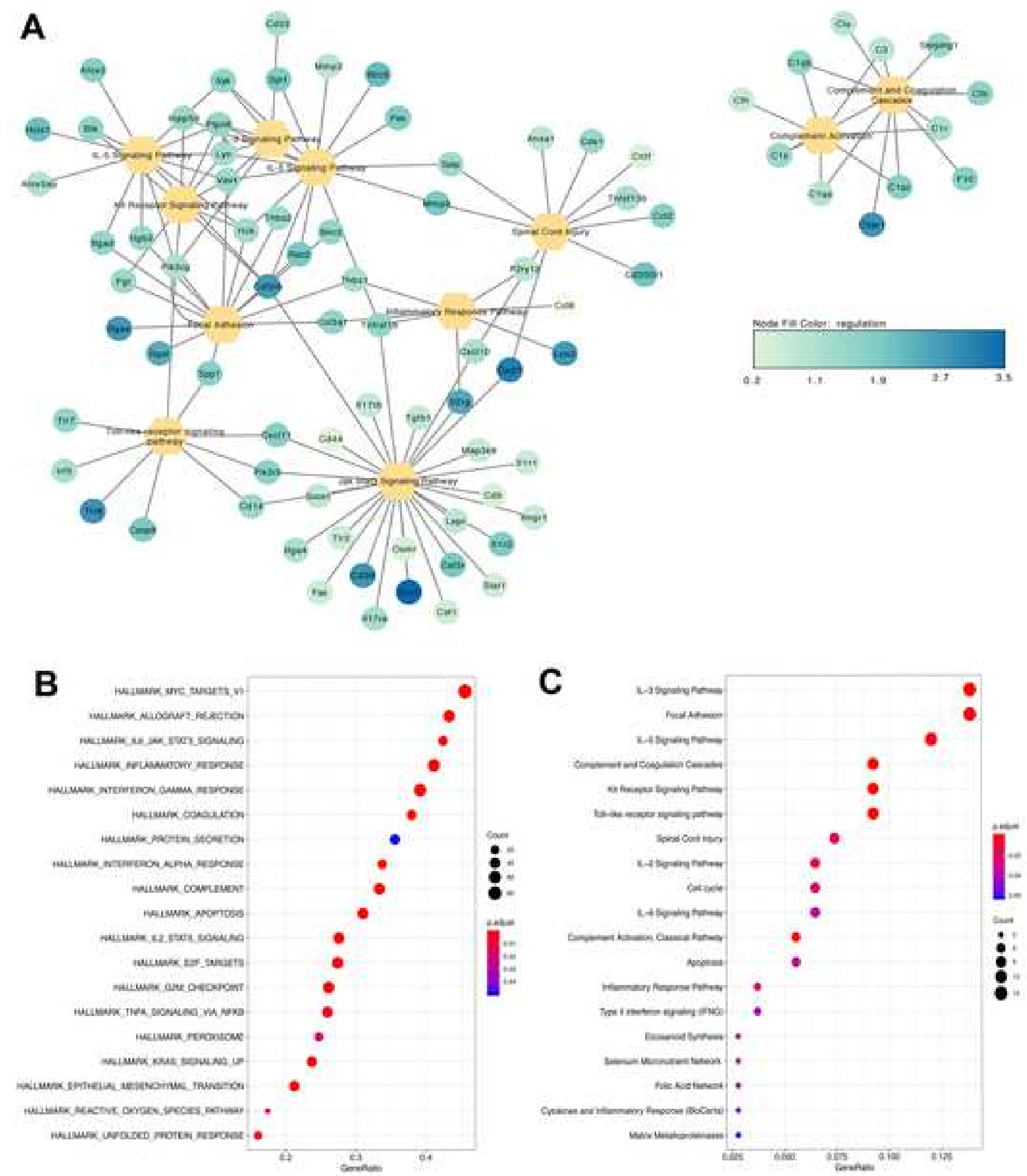


\section{Click here to access/download Supplemental Tables/Figures Berdugo_et_al. Online Supplemental DATA CLEAN.docx}

